\title{
Prevención del delito y teorías criminológicas: tres problematizaciones sobre el presente
}

\author{
Crime Prevention and Criminological Theories: Three Issues \\ for the Current Time \\ Prevenção do delito e teorias criminológicas: três problematizações \\ sobre o presente
}

EMILIO JORGE AYOS*

Instituto de Investigaciones Gino Germani, Universidad de Buenos Aires

FECHA DE RECEPCIÓN: 25 DE JUNIO DE 2013 • FECHA DE ACEPTACIÓN: 22 DE ABRIL DE 2014

Doi: dx.doi.org/10.12804/esj16.02.2014.09

Para citar este artículo: Ayos, J. E. (2014). Prevención del delito y teorías criminológicas: tres problematizaciones sobre el presente. Estudios Socio-Jurídicos, 16(2), 265-312. Doi: dx.doi.org/10.12804/esj 16.02.2014.09

\section{RESUMEN}

Toda estrategia de prevención del delito supone, explícita o implícitamente, la reelaboración de la pregunta sobre qué es el delito, cuáles son sus causas y cómo conjurarlo. En este trabajo, nos dedicaremos a ubicar, en el saber criminológico, los 'materiales' que han sido reactualizados para construir estas formas de problematización que atraviesan las modalidades de intervención que pusieron en marcha las políticas de prevención social del delito en la Argentina contemporánea. Proponemos tres mojones: en primer lugar, la sociología criminal positivista de Enrico Ferri, en particular su teoría de los 'equivalentes de las penas'; la problematización de la prevención del delito en la sociología de la llamada 'Escuela de Chicago', centrándonos en el trabajo de Frederic Thrasher; y, por último, la mirada sobre la 'intervención multiagencial' contra el delito en los autores referenciados en la criminología realista de izquierda, especialmente sobre Jock Young, Roger Matthews y John Lea. Estas producciones comparten, a su vez, el haber abordado la cuestión de la 'prevención del delito' de manera específica en sus trabajos. El criterio de selección y los ejes de comparación surgieron de los emergentes de una investigación empírica mayor, la cual tuvo por objetivo

* Doctor en Ciencias Sociales (UBA); magíster en Política Social (UBA); licenciado en Sociología (UBA); becario de posdoctorado del Consejo Nacional de Investigaciones Científicas y Técnicas en el Instituto de Investigaciones Gino Germani (UBA). Docente de la Facultad de Ciencias Sociales de la Universidad de Buenos Aires, de la Universidad Nacional de Mar del Plata y de la Universidad Nacional de General Sarmiento; investigador del Grupo de Trabajo de Clacso "Posneoliberalismo y políticas de control de delito en América del Sur". Dirección postal: calle Brasil 410, piso 3², departamento C, Ciudad Autónoma de Buenos Aires (Argentina). Código Postal 1154. Teléfono: 005411-32212714. Correo electrónico: emilio.ayos@gmail.com 
analizar los modos de problematización de la relación entre delito y condiciones de vida en el desarrollo de las políticas de prevención social del delito en Argentina, durante la primera década del nuevo siglo. Los ejes comparativos referidos fueron fundamentalmente tres: el lugar de la política social y la intervención sobre las condiciones de vida en las estrategias preventivas; la modalidades de construcción de las poblaciones objetivos; $\mathrm{y}$, por último, las formas de territorialización que presentaban dichas políticas.

Palabras clave: prevención del delito, criminología, políticas sociales.

\section{ABSTRACT}

Any crime prevention strategy implies, explicitly or implicitly, the question about what crime is, the causes of it and how to avert it. In this paper we will focus on set, thru criminological theories, the "concepts" that have been renewal to build different answers to such questions, particularly on crime prevention's policies in contemporary Argentina. We suggest three axes: first, the criminal positivist sociology of Enrico Ferri, particularly his idea of " penalties equivalent,"; second, the discussion about crime prevention in the "Chicago School", specially on Thrasher Frederich's work; and finally, "multi-agency intervention" idea of the left realist criminology, especially Jock Young, Roger Matthews and John Lea. Such productions have in common the fact that the three have specifically discussed the issue of "crime prevention" on their work. The selection criteria and comparison axis emerges from a broader investigation, which aimed to analyze the modes of way that the association between crime and living conditions is addressed on the social crime prevention policies in Argentina, during the first decade of the new century. Three comparatives dimensions were analyzed: the way social policies appears on crime prevention strategies; the ways the target populations are delimited; and last, the ways the intervention territories are defined, building an specific idea of territory.

Key words: crime prevention, criminology, social policies.

\section{RESUMO}

Toda estratégia de prevenção do delito supõe, explícita ou implicitamente, a reelaboração da pergunta sobre que é o delito, quais são as suas causas e como pode se conjugar. Neste trabalho estaremos dedicados a localizar, no saber criminológico, os "materiais" que tem sido reatualizados para construir estas formas de problematização que atravessam as modalidades de intervenção que puseram em funcionamento as políticas de prevenção social do delito na Argentina contemporânea. Propomos três marcos: em primeiro lugar a sociologia criminal positivista de Enrico Ferri, particularmente sua teoria dos "equivalentes das penas"; a problematização da prevenção do delito na sociologia da nomeada "Escola de Chicago", nós centrando no trabalho de Frederich Thrasher; e finalmente, a mirada sobre a "intervenção multiagencial" contra o delito nos autores referenciados na criminologia realista de esquerda, especialmente sobre Jock Young, Roger Matthews e John Lea. Estas produções compartem, ao mesmo tempo, ter abordado a questão da "prevenção do delito" de forma específica em seus trabalhos. O critério de seleção e os eixos de comparação surgiram dos emergentes de una pesquisa empírica maior, a qual teve por objetivo analisar os modos de problematização da relação entre delito e condições de vida no desenvolvimento das políticas de prevenção social do delito na Argentina, durante a primeira década do novo século. Os eixos comparativos referidos foram fundamentalmente três: o lugar da política social e a intervenção sobre as condições de vida nas estratégias preventivas; as modalidades de construção das populações objetivo; e finalmente as formas de territorialização que apresentavam ditas políticas.

Palavras-chave: Prevenção do delito, criminologia, políticas sociais. 


\section{Introducción}

Toda estrategia de prevención del delito supone, explícita o implícitamente, la reelaboración de la pregunta sobre qué es el delito, cuáles son sus causas y cómo conjurarlo. En sus discursos institucionales, o a través de sus prácticas de gestión, la política de prevención del delito (como toda política) conforma grillas de inteligibilidad a partir de las cuales se definen sus objetos de intervención. En este trabajo, nos dedicaremos a ubicar, en el saber criminológico, los 'materiales' que han sido reactualizados para construir estas formas de problematización que atraviesan las modalidades de intervención que pusieron en marcha las políticas de prevención social del delito en la Argentina contemporánea. En este sentido, propondremos una particular clave de lectura sobre estos cuerpos de teoría social, que supone encadenamientos y distinciones que cobran sentido a la luz del resultado de nuestra investigación empírica, la cual, a la par, iremos desarrollando. En las líneas siguientes, adelantaremos la conceptualización emergente sobre las líneas de continuidad y las disrupciones que (re)interpretamos sobre estas producciones del saber criminológico.

En el marco de la proliferación de políticas inscriptas en el paradigma de la prevención 'extrapenal' del delito desde mediados de la década de los setenta del siglo pasado, las estrategias de prevención 'social' se han diferenciado por retomar la cuestión de las 'causas sociales' del delito, es decir, por orientarse hacia sus supuestos orígenes estructurales-sociales. Esto las diferenció de las políticas preventivas situacionales-ambientales, las cuales, sin dejar de elaborar una concepción sobre el delito, fueron atravesadas por una racionalidad que no solo abandonó la preocupación de los orígenes sociales del delito, sino que se construyó en oposición a esa tradición. Estas referencias sobre las causas sociales del delito en la 'nueva' prevención social no son una novedad: en ellas resuenan las argumentaciones, los posicionamientos y las disputas que se desarrollan dentro del pensamiento criminológico. Cabe decir que estas argumentaciones corresponden a diferentes inscripciones disciplinarias y de enfoques, como doctrina jurídico-penal, sociología criminal, antropología criminal, sociología de la desviación o de la reacción social, o criminología crítica; como así también que su encabalgamiento y sus consecuencias en relación con las políticas de control del delito es una cuestión problemática, con desplazamientos y mediaciones, 
abierta a las diferentes dinámicas históricas. En las formas específicas en que son problematizadas las 'causas' sociales del delito en las estrategias de prevención contemporáneas, se reactualizan de manera particular (a partir de ciertas aperturas y obturaciones, bloqueos y desbloqueos) las diferentes voces que elaboraron esta cuestión en la teoría criminológica, particularmente en las diferentes polémicas que la estructuraron. A partir de esta problematización, a su vez, se organizaron las distintas construcciones sobre la idea de 'prevención del delito' que de la misma manera proliferaron con continuidades y rupturas.

En el presente trabajo, reconstruiremos tres producciones dentro del discurso criminológico que son retomadas en la problematización de la que participan las estrategias de prevención del delito en la Argentina de la última década. Nos planteamos la pregunta acerca de qué producciones del saber criminológico sobre la prevención del delito se anudan y se reactivan estratégicamente en la emergencia de estas políticas. Pretendemos ubicar los diferentes ejes, en tanto distintas tradiciones criminológicas, que estructuran sus modalidades de intervención. En este sentido, nuestro objetivo será ubicar una clave de inteligibilidad para los debates actuales en los que se inscriben las políticas de prevención social del delito, en especial, acerca de los modos de problematización de la relación entre condiciones de vida y delito.

Así, no nos proponemos hacer un relevamiento exhaustivo de las 'escuelas' criminológicas, sino identificar algunas líneas argumentales que se muestran como particularmente relevantes para nuestro problema de investigación. Proponemos tres mojones para realizar esta reconstrucción: en primer lugar, la sociología criminal positivista de Enrico Ferri, en particular su teoría de los 'equivalentes de las penas'; en segundo lugar, la problematización de la prevención del delito en la sociología de la llamada 'Escuela de Chicago', centrándonos en el trabajo de Frederic Thrasher; y, por último, la mirada sobre la 'intervención multiagencial' contra el delito en los autores referenciados en la criminología realista de izquierda, especialmente sobre Jock Young, Roger Matthews y John Lea. Estas producciones comparten, a su vez, el haber abordado la cuestión de la 'prevención del delito' de manera específica en sus trabajos.

La identificación de estas tres elaboraciones conceptuales surge como resultado de nuestra investigación empírica sobre el desarrollo de los 
programas preventivos en Argentina durante el período 2000-2010 y el vínculo que estas establecieron con el campo de las políticas sociales, particularmente con los programas asistenciales laborales (Ayos, 2009, 2010, 2011, 2012a, 2012b, 2013a, 2013b). No podemos aquí desarrollar en profundidad las formas de problematización sobre la relación entre condiciones de vida y delito que mostraron estos resultados de investigación. Pero sí marcaremos las dimensiones o ejes problemáticos fundamentales que orientaron el análisis de las teorías criminológicas que en este artículo presentamos. El primer eje de análisis fue el papel de las políticas sociales en las modalidades de prevención del delito. Nos referimos al lugar que le es asignado a las intervenciones sociales del Estado en los 'mecanismos preventivos' propuestos por la política criminal y los encadenamientos causales que se desprenden de ella. Sin poder extendernos, solo diremos que los resultados de nuestra investigación muestran una tensión entre una forma de problematización centrada en la intervención sobre las condiciones de vida de los sujetos y grupos (en tanto mejoramiento de sus ingresos, de sus condiciones de vivienda, de su acceso a la educación o a empleos de calidad protegidos por la seguridad social) como mecanismo preventivo, frente a una problematización que presenta a las políticas sociales como una mera 'herramienta' que atrae a los jóvenes a los dispositivos (las entrevistas individuales, los talleres informativos o de discusión, las reuniones grupales o los proyectos recreativos) donde el trabajo sobre su subjetividad adquiere total protagonismo como mecanismo preventivo (Ayos, 2009, 2013a). El segundo eje se vincula con las formas de construcción de la población objetivo. Aquí las tensiones se observan entre formas más generalistas de definir los sujetos destinatarios de la intervención (en tanto intervenciones de política social que afectan al conjunto de sectores populares y trabajadores) frente a miradas que recortan diferentes poblaciones en torno a sus características específicas, entre las que se cuenta su vínculo con las prácticas delictivas. Por último, nos orientó la cuestión de las modalidades de territorialización que desarrollaron estas intervenciones preventivas en Argentina. En este sentido, nos preguntamos por la forma en que estas políticas entendieron la dimensión territorial de su intervención, pendulando entre una mirada extendida, ampliada, de los territorios de intervención, teniendo a la noción de sociedad como referencia conceptual (como de manera clásica muestran las políticas de seguridad social, a las que alude significativamente Ferri, según 
luego veremos); contra una territorialización segmentada (Ayos, 2012a) que recorta espacios sociales y urbanos definiendo sus características específicas, aludiendo de manera recurrente a la noción (permanentemente reactualizada, reelaborada) de comunidad. Esta última forma de problematización ha mostrado su anudamiento con la centralidad de la cultura como dimensión que caracteriza a estos territorios segmentados (y esta es la clave que marca nuestra identificación de la producción de la Escuela de Chicago y luego del Realismo de Izquierda).

Quisiéramos en este momento adelantar uno de los hallazgos fundamentales que este artículo se propone desarrollar: en estas tres producciones conceptuales ya clásicas sobre la prevención del delito, es posible trazar una línea de continuidad en cuanto a dos dimensiones que son características definitorias de las políticas de prevención en la Argentina contemporánea: en primer lugar, tienen en común, elaborar una interpretación sobre la prevención del delito desde un discurso científico-sociológico, asentado en la centralidad de la sociología como ciencia, como conocimiento científico que puede mostrar las 'verdaderas' causas de los problemas sociales. En segundo lugar, es posible identificar un posicionamiento progresista, que confía en la reforma social como respuesta al conflicto. En relación con su carácter sociológico, este se configura en contraste con la tradición del saber jurídico centrado en el campo del derecho (Melossi, 1997), aunque sus cruzamientos son recurrentes. Con la noción de progresismo intentamos recuperar aquel sentido de una fe eminentemente moderna en el progreso, de una confianza (y una apuesta) en el proyecto moderno, como camino hacia un futuro siempre mejor, que, a finales del siglo XIX, conjuga la 'reforma social' como vehículo de esa transformación lenta pero segura, progresiva, hacia las promesas de la modernidad. ${ }^{1}$ La noción de prevención es heredera de esta mirada, como nos recuerda Tamar Pitch (2009): "La prevención, en suma, es un imperativo y una práctica capital de la modernidad, allí donde los saberes científicos, sociales y no sociales, resultan 
producidos y utilizados para conocer el presente en función de un control del futuro" (Pitch, 2009, pp. 42-43). De esta manera, la idea de progresismo nos permite dar cuenta de esta línea de fuerza que, con muchas dispersiones y re-creaciones, atraviesan las problematizaciones que hemos seleccionado. Por ello (aunque siempre tiene algo de arbitrario marcar un punto de inicio), comenzamos con el pensamiento positivista y socialista de Enrico Ferri. Como luego analizaremos, esta articulación entre la idea de las 'causas del delito' y reforma social es reactualizada en las estrategias de prevención social en Argentina durante la última década.

Como ya adelantamos, este trabajo es producto de una investigación mayor, y muestra la elaboración conceptual que la sustentó. Esta investigación tuvo por objetivo analizar los modos de problematización de la relación entre delito y condiciones de vida en el desarrollo de las políticas de prevención social del delito en Argentina, durante la primera década del nuevo siglo, entendiendo estas estrategias preventivas como espacios de intersección entre la política criminal y la política social. El vínculo entre el delito y las condiciones de vida de los supuestos ofensores es uno de los puntos nodales de los debates en torno a la llamada 'cuestión de la inseguridad' en la Argentina contemporánea. La emergencia de esta problematización acerca de la peligrosidad de los sectores populares en nuestro presente reactualiza diversas líneas de fuerza sobre un viejo problema, caro a la conformación de la cuestión social decimonónica: las clases peligrosas. Por ello, en esta investigación, nos preguntamos bajo qué formas las condiciones de vida de los sectores populares son problematizadas en términos de su peligrosidad, específicamente en los espacios de intersección de la política social y la política criminal. Estas políticas se constituyen en un punto álgido de la elaboración de los constructos sociales que esta tesis pone en relación. Las políticas sociales en cuanto a la producción social de las condiciones de vida, en esta tensión entre trabajo y pobreza, que reelabora constantemente la cuestión de la autovalía y la dependencia como forma de dirimir la pertenencia legítima de los sujetos en las sociedades capitalistas. Las políticas criminales en la producción social del delito, en tanto administración diferencial de los ilegalismos, que constituye a los sujetos de la peligrosidad. Este 'retorno de las clases peligrosas', en el marco de las profundas reorientaciones neoliberales que ambos campos de políticas muestran desde mediados de la década de 1970, encuentra un espacio 
específico de elaboración en la emergencia de la corriente de la 'nueva prevención' social del delito, problematizando de diferentes modos la relación entre condiciones de vida y delito.

Esta mirada nos permite interrogarnos por las mutaciones históricas generales que se observan en las políticas sociales y criminales, como un eje analítico central para aprehender los procesos en los cuales participan las estrategias de prevención social. Por último, las políticas de prevención social del delito y las formas particulares en que estas reconstruyen la relación entre delito y condiciones de vida emergen en un campo de contradicciones y debates políticos que, en Argentina a partir de los años noventa, se estructuró a partir de dos vectores: en primer lugar, en torno a la noción de 'inseguridad', siendo parte de las orientaciones generales que adoptó la política criminal en el período bajo estudio. En segundo lugar, también surgen del entramado de fuerzas que en el campo de la política social organizó nuevas formas de tematizar la pobreza y el desempleo. Por ello, la reconstrucción histórica de dichos campos se presenta como marco interpretativo ineludible para analizar las políticas preventivas en sus particularidades histórico-políticas.

A partir de este problema de investigación, analizamos las políticas de prevención social del delito durante el período 2000-2010 en su intersección con el campo de las políticas sociales. La periodización encuentra su punto inicial en la creación del Plan Nacional de Prevención del Delito en el año 2000, en un contexto en el que la cuestión de la 'inseguridad' había alcanzado niveles inéditos de politización. El punto final de la periodización se ubica en la creación del Ministerio de Seguridad en el año 2010, dado que expresa una reorientación de las líneas de fuerza que organizan los debates y las políticas criminales. En esa dirección, en este trabajo, analizaremos intervenciones que en su desarrollo se vincularon con el Programa de Empleo Comunitario (PEC) del Ministerio de Trabajo, Empleo y Seguridad Social de la Nación: el Programa Comunidades Vulnerables (PCV Dirección Nacional de Política Criminal), los programas municipales Post Comunidades Vulnerables y la "Intervención multiagencial para el abordaje del delito en el ámbito local" (Secretaría de Seguridad Interior/PNUD). Estos programas preventivos otorgaron a su población objetivo la transferencia de ingresos que preveía el PEC con la condicionalidad de la contraprestación de su participación en las actividades preventivas, como luego desarrollaremos. 
La realización de nuestra investigación empírica - de la cual aquí presentaremos fundamentalmente la elaboración teórica que la organizóadoptó un enfoque metodológico cualitativo. Dados los diferentes ejes que recortan nuestro problema de investigación, hemos diferenciado tres planos de indagación empírica y reconstrucción analítica: el de las condiciones socio-políticas e institucionales generales; el plano que refiere a la cuestión específica de la relación entre condiciones de vida y delito, en términos de sus modos de problematización; $\mathrm{y}$, por último, la dimensión de las formas de problematización que circulan en el desarrollo de políticas específicas de prevención social del delito en Argentina durante la primera década del siglo XXI. Sobre la selección de la implementación de estos programas en diferentes unidades político-administrativas y de gestión, la investigación combinó el uso de fuentes primarias (entrevistas en profundidad a funcionarios y operadores de los programas analizados) y fuentes secundarias de diversos tipos, acordes a los diferentes planos de indagación empírica que hemos señalado. El presente artículo se asienta completamente en esta última técnica, conformando un corpus documental sobre las diferentes concepciones criminológicas que abordamos.

En la siguiente sección, antes de introducirnos en las formas de problematización que emergen de estas producciones criminológicas, reconstruiremos sucintamente las reorganizaciones de los campos de la política criminal y de la política social que, según nuestra investigación, marcaron el desarrollo de la prevención social del delito en el inicio de la década de 2000 en Argentina.

\section{La prevención del delito en Argentina: la reorganización de los campos de la política social y la política criminal}

En los finales de los años noventa, la emergencia de la in/seguridad mostró una de sus características centrales: convertirse en uno los ejes ineludibles de las discusiones políticas y electorales, en tanto capital político en disputa desde diferentes sectores. En estos años, la inseguridad se configura como un objeto destacado del intercambio político, en un proceso que conjuga dinámicas de movilización social y reclamos sociales por mayor punitividad, campañas electorales, búsquedas de consenso y 
legitimación en el desarrollo de políticas, lineamientos de las fuerzas de seguridad y espacios de gestión pública (Font, 1999; Sozzo, 1999; Pegoraro, 2001, Kessler, 2004; Saín, 2008; Guemureman, 2002; Daroqui, 2009; Isla, 2007; Rangugni, 2009; Miguez e Isla, 2010; Galvani, et al, 2010). Así, se produce una reconfiguración de las relaciones entre el 'saber experto' y el desarrollo de políticas, expresada en un proceso que Massimo Pavarini (2006) ha denominado como una novedosa legitimación 'desde abajo', que otorga mayor relevancia a las interpretaciones 'realistas' en que los reclamos, los sentimientos y la 'indignación' de las 'víctimas' tienen un lugar destacado, aunque esto no suponga que las mediaciones y reconstrucciones del campo político y académico desaparezcan en esta producción (Sozzo, 2007; Garland, 2005; Pavarini, 2006; Calzado y Van den Dooren, 2009).

Este proceso de 'politización' de la in/seguridad, y el aumento de los intercambios en torno a ella en tanto campo de enfrentamientos, registra en Argentina dos momentos de particular intensificación: el primero, se configura en el contexto de las campañas electorales nacionales y provinciales (incluyendo la Ciudad Autónoma de Buenos Aires) en los años 1999 y 2000; el segundo, a partir del movimiento social y político que siguiera al secuestro y asesinato de Axel Blumberg en marzo de 2004 (Sozzo, 2007; Saín, 2010; Ayos et al., 2010). El primer momento se configura a partir de ese proceso electoral, en el cual el eje de la in/seguridad fue un componente central, teniendo como expresión paradigmática y, a la vez, más desmesurada, el discurso de 'mano dura' de la campaña electoral de Carlos Ruckauf por la gobernación de la Provincia de Buenos Aires. La frase de Ruckauf que resume la radicalidad de su discurso en materia de seguridad ("Hay que meterle bala a los delincuentes") muestra uno de los puntos más álgidos de este 'giro punitivo' en el discurso político, el que puede inscribirse en una vertiente neoconservadora con amplia difusión no solo en el contexto argentino (Wacquant, 2000). Sin embargo, en este momento de altísima politización e intensificación punitiva, también hubo espacio para líneas en algunos sentidos divergentes, que polemizaron con este discurso de la 'mano dura' y que configuraron cierto campo de enfrentamientos en torno a la 'inseguridad'. Este es el entramado de disputas y debates del que surge la primera política de envergadura nacional de orientación preventiva extrapenal: el Plan Nacional de Prevención del Delito (PNPD), lanzado en el mes de agosto de 2000. El PNPD se presenta como parte de 
un posicionamiento discursivo que construye su campo de adversidad en oposición a la orientación de 'mano dura', fundamentalmente a partir de dos formas argumentativas, distinguidas, por supuesto, solo en términos analíticos: una de corte ético-político en tanto 'política democrática de seguridad', y otra atravesada por una racionalidad técnica, presentando a sus intervenciones como producto de una problematización compleja, ligada al diagnóstico de las ciencias sociales, frente al simplismo de la 'mano dura'. Si este posicionamiento por una politica democrática de seguridad enmarcó el surgimiento de las políticas preventivas en Argentina, el desarrollo de las estrategias de prevención 'social' supuso, a su vez, su acoplamiento con las tendencias preponderantes en el campo de la política social durante su reorganización bajo lineamientos marcadamente neoliberales, centrales desde el inicio de la década de 1990 (Grassi, 2003; Danani, 2004, Cortés y Marshall, 1999; Soldano y Andrenacci, 2006). En particular, retomaron dos ejes fundamentales de este proceso de 'asistencialización' de la política social argentina: las lógicas propias de las políticas tipo workfare y la programática del desarrollo comunitario (Ayos, 2013a).

Con el aumento drástico en las tasas de desempleo que comienzan a registrarse en la segunda parte de la década de 1990, se cristaliza una modalidad de intervención asistencial que hará hincapié en la cuestión del trabajo y los problemas de empleo. Este conjunto de intervenciones se caracterizará por prescribir alguna modalidad de ocupación como parte del plan de asistencia, conceptualizado como contraprestación. Pero más aún, lo que caracterizará a esta modalidad es una racionalidad que reintroduce un fuerte discurso moral sobre el trabajo, siendo su núcleo el sujeto desempleado. El trabajo se constituyó en recurso de la asistencia al establecer una problematización del desempleo en tanto una carencia del propio sujeto (Grassi, 2003). La introducción de esta tradición del workfare ${ }^{2}$ sustentó como racionalidad política los discursos sobre la 'empleabilidad' de los sujetos desocupados y organizó las formas de intervención que, a partir de las contraprestaciones laborales o de capacitación laboral, se centraban en

2 La voz workfare proviene del juego de palabras entre welfare (bienestar, pero también asistencia) y work (trabajo), y es el nombre con que se aludió a la reforma anglosajona de los Estados de Bienestar. Su característica distintiva fue la obligatoriedad para los 'beneficiarios' de realizar una contraprestación laboral o de capacitación laboral como modo de promover su empleabilidad (Grondona, 2012). 
las capacidades y habilidades como carencia subjetiva, que como tal explicaba la situación laboral del desempleado. Por otra parte, esta 'traducción' argentina del workfare (Grondona, 2012) recuperaba aquella vertiente del desarrollo comunitario, que rearticulaba la cuestión de la activación comunitaria con los procesos de responsabilización subjetiva respecto del trabajo (expresados en la noción de empleabilidad como cualidad individual), a contramano de los procesos que instaron las intervenciones inscriptas en la lógica del seguro social que, aunque contenía diferentes orientaciones históricas, implicó procesos de socialización de los riesgos en la configuración de los Estados de Bienestar (Grassi, 2003; Donzelot, 2007). Esta doble articulación entre desarrollo comunitario y workfare marcó fuertemente al Programa de Empleo Comunitario, intervención central dada su articulación con los desarrollos de prevención social del delito en Argentina. Estos programas preventivos otorgaron a su población objetivo la transferencia de ingresos que preveía el PEC con la condicionalidad de su participación en las actividades preventivas (talleres, proyectos, entrevistas individuales) en tanto contraprestación (Ayos, 2013a). En las secciones siguientes, rastrearemos estas líneas de fuerza en las discusiones y problematizaciones del saber criminológico que ha abordado la cuestión de la prevención del delito de manera específica, reactualizadas en las políticas preventivas.

\section{Tres problematizaciones sobre el presente}

\subsection{Enrico Ferri y los equivalentes de las penas}

Nos parece pertinente comenzar con un rasgo de la construcción de Ferri. En su Sociología criminal (1907) de 1884, específicamente en su teoría de los equivalentes de las penas, se muestra un enfoque que abre el camino a las problematizaciones sobre la prevención del delito, como línea de continuidad, como marca que es retomada hasta nuestros días. Sostendremos que el posicionamiento político en pos de la prevención del delito que enmarca los programas preventivos en Argentina, el cual entiende a la prevención como el opuesto a las respuestas punitivistas, mediante una argumentación ético-política (en tanto posicionamiento progresista), pero también mediante una alusión al saber científico sobre lo social (intentando 
mostrar las causas verdaderas, sociales, del delito), puede rastrearse hasta esta formulación de los equivalentes de la pena de Ferri.

En este sentido, el texto de Ferri puede leerse, en primer lugar, como un intento de constituir la dicotomía represión-prevención, en tanto oposición entre pena y equivalentes de la pena (preventivos). En la manera en que el autor recrea como oponente a la 'Escuela Clásica', refiriéndose fundamentalmente a Beccaria ([1764] 1976), construye como su campo de adversidad la articulación clásica entre delito y pena, y a las propiedades preventivas simbólico-disuasivas que, en términos generales, esta corriente asigna a la pena. Si en ella la represión con el instrumento de la pena no se enfrenta a la idea de prevención, sino que es uno de los fines que intenta lograr, en Ferri, se observa la apuesta por demarcar firmemente la oposición entre represión y prevención, por crear una dicotomía. Esta creación se sustentó en una apelación al conocimiento científico y, en particular, en la sociología. Pero, a su vez, se organizó desde los postulados de un progresismo socialista. Por ello, su crítica se centra en la ineficiencia de la respuesta punitiva, en tanto que considera que las penas son formas sumamente limitadas de combatir el delito.

Si bien esta respuesta punitiva es la panacea de los criminalistas clásicos, los legisladores y el público, según dice Ferri, el sociólogo criminalista, a partir de la observación positiva de los hechos y su génesis 'natural', juzga como evidentemente necesarios 'otros medios de defensa'. En esta misma línea, hace referencia a la equívoca relación entre la suavidad de las penas y la proliferación de los delitos; idea que sobreviene como uno de los rasgos salientes en el discurso 'progresista' de la actualidad en su oposición a la retórica de la 'mano dura' o la 'tolerancia cero'. Así, argumenta a favor de un abordaje de la cuestión criminal desde el flanco: la vida cotidiana nos enseña que para hacer "menos perniciosa la explosión de las pasiones, es preferible abordarlas de flanco, en su mismo origen, que atacarlas de frente" (Ferri, 1907, pp. 291-292). El argumento sostiene que la estrategia más productiva para atacar los 'orígenes' del fenómeno criminal no es la represión a partir de las penas que establecen las normas que aplica el sistema penal, sino el descentramiento de la cuestión de la pena y el avance por su flanco, por su lateral. Para sostener esta posición, recurre a numerosas analogías, como la del 'marido inteligente' que sabe que tiene recursos mejores para mantener la fidelidad de su esposa que la figura penal del adulterio, o el 
'maestro de industria' que conoce la mayor efectividad de la participación en las ganancias que las multas o los castigos para una producción más satisfactoria de los trabajadores. Estos ataques por el 'flanco' Ferri los considera verdaderos 'equivalentes' de las penas, en el sentido de que previenen el delito en sus causas, evitando la acción penal.

Ferri reconstruye la lógica clásica entre delito y pena en tanto oposición del impulso criminal por el impulso penal, es decir, la oposición directa de fuerzas contrarias. Esta articulación retoma el modelo del intercambio mercantil, en este caso entre delito y pena, bajo la lógica del contrato expresada claramente en Beccaria (Pavarini, 1983). La teoría de los equivalentes de las penas de Ferri, en cambio, sostendrá la eficacia de intervenir en los orígenes de los comportamientos criminales a partir de una estrategia 'indirecta', dada la futilidad de ese ataque de 'frente', de esa fuerza inversa que representan las sanciones penales.

De esta forma, el autor reconstruye una dicotomía entre represión y prevención, esta última materializada en los equivalentes de las penas. La idea de represión penal es cuestionada, por un lado, en términos ético-políticos, a partir de su mirada socialista. En ella, la criminalidad endémica encuentra sus orígenes sociales en la desigualdad del orden burgués, aunque en la perspectiva positivista de Ferri siempre existe un resto de criminalidad natural o atávica. En segundo lugar, la respuesta penal es objetada también desde argumentos científicos, apoyándose en el método positivo de la sociología, la cual, a partir del estudio del organismo social, muestra a la represión penal como forma de intervención que no trata con sus verdaderos orígenes. De aquí, la relevancia de la noción de 'causas sociales' de la criminalidad: el delito es un fenómeno que, como cualquier otro, tiene causas objetivas, las cuales solo pueden atacarse a partir de la reforma social, entendiendo a esta como 'equivalente' de las penas.

Así, la teoría de los equivalentes de las penas se enmarca en un reformismo basado en un marxismo de fuerte cuño evolucionista. Por un lado, estos equivalentes tienen sentido en tanto que "el edificio social no sea radicalmente transformado en sus bases económicas y, por consiguiente, morales, políticas y jurídicas, según los datos y previsiones de la sociología socialista", aunque esto no les quita relevancia, dado que no sería justo entenderlas como 'simples paliativos', ya que estas servirán como estrategias de transición práctica y gradual hacia la metamorfosis social, pues las 
sociedades, como todos los organismos, "son susceptibles sólo de transformaciones parciales, que, no obstante, acumulándose y completándose recíprocamente, constituyen las diferentes fases de la evolución social" (Ferri, 1907, p. 294). Así, estos equivalentes son entendidos, no como un punto de llegada de una reforma social superficial, sino como el punto de inicio de un orden nuevo, que "... se alcanzará adoptando la propiedad colectiva de los medios de producción y de trabajo, y en su consecuencia, asegurando las condiciones de vida verdaderamente humanas a todo ser humano" (Ferri, 1907, p. 295).

Estos equivalentes de las penas tendrán efectos en los 'factores sociales' que causan la criminalidad, o dicho de otra manera, sobre la criminalidad que tiene orígenes sociales; en cambio, y dada la 'ley de saturación criminal', dejaría sin modificar ese minimum de criminalidad natural y atávica que habita en todo medio social. Es decir, los equivalentes de las penas, como estrategia que favorece la transición de una sociedad burguesa a una socialista, tienen capacidad para combatir las formas endémicas de la criminalidad, las cuales desaparecerán por completo con la consolidación de la fase socialista de la evolución de las sociedades. No así, las formas agudas o esporádicas propias de patologías de determinados individuos, para los que solo las penas y la prisión representan el último recurso de defensa social. En esta cadena que articula criminalidad endémica, equivalentes de las penas, reforma social, prevención, evolución y socialismo, se expresa lo que Ferri nombrará como los tres transformismos: el marxismo, como 'transformismo económico'; el darwinismo, en tanto 'transformismo biológico'; y el spencerismo, como 'transformismo universal'.

Entonces, observamos cómo este discurso socialista evolucionista, reformista y también sociológico (porque como vimos es la 'sociología socialista' la que otorga los datos y previsiones del desarrollo evolutivo de las sociedades) es la trama en la que se construye la idea de una prevención del delito que, opuesta a la represión penal tanto por esta dimensión científico-técnica de la sociología positiva como por las concepciones ético-políticas socialistas ("asegurando las condiciones de vida verdaderamente humanas a todo ser humano..."), se plantea la cuestión de las causas sociales del delito.

Aunque luego lo retomaremos, nos detenemos por un momento para señalar que, al separar represión de prevención, esta racionalidad política que construye el entramado en el que se anudan sociología positiva- 
socialismo evolucionista-reforma social-prevención social del delito se hace parte de ese proceso general descrito por Donzelot (2007) de invención de lo social; es decir, la creación de un espacio, de un ámbito entre lo civil y lo político. Esta configuración puede modelizarse en la idea de que no es a partir del mero ejercicio de la soberanía estatal en la aplicación de la ley penal que va a encontrar un fundamento para el desarrollo de la república: la invención estratégica de lo social viene a aportar un espacio de intervención y es en este espacio de intervención que es recreado, aunque fragmentariamente todavía, en la apuesta de Ferri sobre la oposición entre represión y prevención.

Ferri organiza los ejemplos de equivalentes de las penas en diferentes 'órdenes': económico, político, científico, civil y administrativo, familiar y educativo. Como interpretación general de estos, podemos decir que se observa un fuerte énfasis en la importancia de las reformas equivalentes de las penas referidas al mejoramiento económico de las condiciones de vida de los trabajadores y en sus condiciones de trabajo y contratación. Por otro lado, Ferri descentra en términos de su efectividad a las acciones ligadas a promover cierta 'moralización' de las clases populares, señalando además la debilidad de la educación como equivalente de la pena, en contraste con la fuerza que tienen las condiciones de vida y del trabajo asalariado como uno de los determinantes del delito.

Introduciéndonos en sus desarrollos específicos, en relación con los equivalentes de las penas de orden económico, se observa la idea de la asociación entre el delito endémico y la pobreza ocasionada por las condiciones del trabajo asalariado, teniendo en cuenta los momentos de desocupación como parte de esas condiciones. Es decir, las formas que adquiere el trabajo asalariado como una de las determinaciones fundamentales de los delitos contra la propiedad específicamente, dado que, es necesario aclararlo, en Ferri hay un determinismo multifactorial (Baratta, 1986; Anitua, 2005). El autor recomienda la promoción del librecambio comercial, entendido como lucha contra los monopolios en su función de bajar el precio de mercancías fundamentales para la reproducción de los trabajadores, denotando cierta influencia del liberalismo económico en el pensamiento de Ferri, que no puede decirse que sea ajena al socialismo del cambio de siglo.

Esta centralidad de las condiciones de vida de los trabajadores se expresa también en Ferri en un punto que resulta particularmente significativo 
para nuestra investigación, en cuanto se refiere al campo de la política social y, en términos más generales, a ese proceso de gestación histórica de una dimensión de lo social en la realidad. El autor refiere a la seguridad social, al ámbito de intervenciones a partir de la técnica aseguradora, el seguro social, como formas de prevención del delito:

Las sociedades cooperativas y de socorros mutuos, las cajas de previsión y para la vejez, las cajas para los inválidos del trabajo, la responsabilidad civil de los contratistas y patronos, mejor y más prontamente aplicada en los accidentes de trabajo, los bancos populares y de ahorro, los comités de trabajo que dan subvenciones bajo forma del mismo, impedirían también, bastante mejor que el Código Penal, un enjambre de delitos ocasionales contra la propiedad y las personas (Ferri, 1907, p. 314).

Nos interesa remarcar algo que luego retomaremos: esta referencia al sector de la seguridad social dentro del campo de la política social se presenta como un elemento que no es retomado en las modalidades posteriores en que es problematizada la relación entre prevención del delito y política social. Como observaremos, las políticas preventivas se articularon históricamente con desarrollos específicos dentro de otro sector de la política social, el cual es parte de una tradición diferente: la asistencia. En el mismo sentido, aparece la construcción de la 'legislación social previsora' como un verdadero 'código' de equivalentes de las penas.

Esta referencia a la seguridad social, al conjunto de intervenciones ligadas al conjuro de las incertidumbres propias de las condiciones de vida de los trabajadores asalariados, es decir, a la socialización de los riesgos mediante la técnica del seguro y el establecimiento de derechos sociales, es un rasgo que luego se desvanece en las problematizaciones sobre la prevención del delito que analizaremos en las secciones siguientes y en las discusiones actuales sobre prevención. La vinculación que las políticas preventivas establecieron con el campo de la política social hicieron pie en la asistencia en tanto 'sector' de políticas, pero también como grilla de inteligibilidad con una tradición específica, ligada a la evaluación de 'medios' y de comportamientos, y especialmente orientada hacia la producción y administración de ese espacio social del no trabajo o de la dependencia (Fraser, 1997). Y, a su vez, otra clave para interpretar esta diferencia se refiere a la cuestión de la 
'escala en la criminología urbana' (Valverde, 2011), una dimensión que es central para el campo de la prevención del delito, pero que en Ferri significativamente no se encuentra: la cuestión de lo 'local' o lo 'comunitario'. La mirada macrosociológica de Ferri imagina la articulación con las políticas sociales como 'equivalentes de las penas', refiriendo a la intervención de seguridad social, sin aparecer las ideas que luego hegemonizaron el enfoque preventivo: la noción de programa local o comunitario. Siguiendo el par conceptual anglofoucoultiano de social-postsocial (Rose, 1996; De Marinis, 2004), la mirada de Ferri reconstruye un territorio de gobierno extendido, incluyente, plenamente social. Aunque lo social, es importante subrayarlo, es también un constructo compuesto, que ensambla diferentes tradiciones.

La reflexión acerca de la relación entre alcoholismo y criminalidad que realiza Ferri es otro de los puntos en los que se expresa un descentramiento de la dimensión 'moral' e individual como 'equivalente de las penas'. Nos interesa señalarlo porque esta tensión entre condiciones de vida y elementos subjetivos atraviesa el campo de la prevención del delito hasta nuestros días. El alcoholismo es entendido como un producto de las condiciones sociales de existencia de las clases populares en el capitalismo, en el sentido del embrutecimiento que produce la explotación en los sujetos.

Así, la intervención sobre la dimensión psicológica, reflejada en los intentos de moralización de las clases trabajadoras a partir de campañas contra el consumo de alcohol, es entendida como un 'mecanismo preventivo' muy débil en comparación con la transformación de las condiciones sociales.

Como adelantamos, la forma en que Ferri tematiza a la educación como equivalente de las penas es otra de las construcciones que marcan el descentramiento de la dimensión individual en su problematización. El autor dedica varias páginas a la cuestión, aunque sus primeras líneas se dedican a subrayar el pobre papel que puede alcanzar la educación como determinante de la conducta individual, más allá de la influencia más potente que ejercen las "condiciones de existencia determinadas por el medio físico y social". En cuanto a la problemática de la educación de la infancia abandonada, propone la tesis de que este fenómeno, en su forma epidémica, es producto del 'industrialismo contemporáneo', el cual impone condiciones de trabajo ('de día y de noche') a los hombres y a las mujeres que terminan destruyendo la vida de la familia y el consiguiente abandono de los hijos ("al obligar a los hijos de los proletarios a crecer en el arroyo"). El único 
'remedio radical' que identifica es el restablecimiento de la 'vida familiar' a partir de la elevación del nivel de la 'vida popular' (Ferri, 1907, p. 333).

De esta manera, en los diferentes equivalentes de las penas que hemos repasado, se organiza el discurso que hará eje en la oposición entre lo penal-represivo y estos desarrollos de 'prevención social' del delito. Tal es así que imagina la idea de que todas estas medidas se organicen en un verdadero 'código preventivo' que se opusiera punto por punto al Código Penal. Así, destacando los 'factores sociales del crimen', Ferri subraya que el centro de las acciones contra el delito debe ser por fuera del Código Penal: la observación, la estadística y el análisis científico indican que "las leyes menos eficaces para impedir los delitos son las leyes penales", en términos de que ellas solo tienen un papel puramente negativo y reactivo, siempre llegando tarde. Es decir que se plantea la tensión entre una intervención penal, negativa, reactiva, ineficaz, no acorde al conocimiento científico, $y$, en el polo opuesto, otra intervención preventiva, positiva, social, eficaz, racional y científica. Aparece la metáfora entre las penas como remedio siempre problemático y la prevención social, la reforma social, en cambio, en tanto higiene, que es más eficaz en neutralizar los orígenes de la enfermedad, mostrando la línea de fuerza biologicista y medicalizante que atraviesa la noción de prevención positivista en Ferri: "Para la defensa social contra la criminalidad y para la elevación moral de las poblaciones, el más insignificante progreso en las reformas de prevención social vale cien veces más y mejor que la publicación de todo un código penal" (Ferri, 1907, p. 337).

De este modo, vemos emerger en Ferri la primera elaboración acerca de la prevención social del delito en términos explícitos bajo una mirada atravesada por la sociología positiva y un reformismo socialista (marxista) de corte evolucionista. Esta mirada macrosociológica, que hace foco fundamentalmente en las condiciones de vida y del trabajo asalariado, y que imagina el vínculo con la política social a partir del prisma de la seguridad social, aparece desdibujada en las problematizaciones que analizaremos a continuación, que reactualizan la oposición entre represión y prevención, pero a partir de una perspectiva que cambiará de escala, priorizando lo 'local', las 'zonas' o las 'comunidades' como forma de territorialización de las intervenciones. Y esta discontinuidad es una marca de las políticas contemporáneas de 'nueva prevención': si bien en ellas es posible identificar la oposición (ético-política y vinculada al saber científico) entre prevención 
y represión, el hincapié en la transformación de las condiciones de vida y de trabajo, la centralidad de la seguridad social como sector de política social y un territorio extendido, plenamente 'social', no son elementos que aparezcan reactualizados en las políticas estudiadas (Ayos, 2009).

\subsection{Thrasher y la Escuela de Chicago}

La sociología de Frederic Thrasher se inscribe en la producción sociológica conocida como la 'Escuela de Chicago' y, aunque con elementos de contacto que luego analizaremos, diverge de la tradición positivista que caracterizaba a Ferri. Una de las particularidades fundamentales que muestra el discurso sobre la cuestión criminal que construyeron los intelectuales de la 'Escuela de Chicago' durante las primeras décadas del siglo XX en los Estados Unidos fue su elaboración como discurso plenamente 'sociológico', que a su vez se construyó como un abordaje autónomo y diferenciado del discurso que había concentrado el enfoque 'sociológico' en el ámbito europeo, la criminología positivista. Esta particularidad se sustentaba en el vínculo que dicha Escuela estableció con el pragmatismo como corriente filosófica propiamente norteamericana. Su diálogo con los llamados 'pragmatistas de segunda generación', como George H. Mead y John Dewey, se reflejó en la impronta metodológica que impregnó su sociología. La posición epistemológica ligada a la idea de 'experiencia', en la cual el conocimiento es una construcción de un sujeto activo que elabora constantemente la gestación de verdades en el desarrollo de sus prácticas, se tradujo en un enfoque sociológico en el que la forma de conocimiento del mundo social era la participación y el desmenuzamiento de esas prácticas concretas que lo constituyen, de ahí su fuerte inclinación hacia la investigación 'empíri-

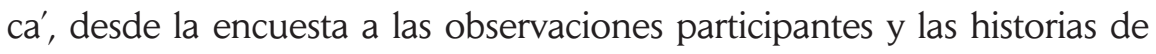
vida. Este es uno de los puntos de partida para comprender a la 'ciudad', y aun las 'áreas' o 'comunidades', como categorías analíticas significativas de su sociología, a diferencia de la tradición europea que, como vimos en Ferri, se movía en los términos generales de una 'sociedad' (Anitua, 2005; Sozzo, 2008b).

Otra de las dimensiones características que configuran a este discurso como plenamente sociológico se inserta en un campo de discusiones también propio de los Estados Unidos. Dario Melossi (1995) analiza cómo el 
discurso de los intelectuales de la 'era progresista' (entre finales del siglo XIX y la Primera Guerra Mundial en los Estados Unidos), y en especial los sociólogos de Chicago, adoptaron un enfoque 'democrático radical' en respuesta a las transformaciones profundas que se desarrollaban en la sociedad norteamericana. Este se situaba en el rechazo de la tradición estadocéntrica europea, centrada en las nociones de soberanía y de derecho, y ponía el énfasis en los procesos de construcción concretos del consenso y la integración:

En la primera página de la importante obra Introduction to the science of sociology, que era el compendio de la nueva sociología de la Universidad de Chicago, Robert E. Park y Ernest W. Burgess señalaban que la sociología había surgido a causa del fracaso de los controles políticos y legales. Sin el conocimiento de las regularidades sociales del comportamiento humano, afirmaban, los gobiernos carecen por completo de poder y se ven incapaces de habérselas con una era de movimientos y organizaciones sociales (Melossi, 1995, pp. 149-150).

La racionalidad política que subraya los procesos de control social situados, concretos, a partir de diversas formas de 'ingeniería' y planificación social para enfrentar lo que es problematizado como la cuestión de la 'integración' y la 'desorganización social', como luego veremos, y que lo contrapone con la centralidad en el Estado, la soberanía y el derecho, ya atravesaba el pensamiento de Ferri y es el sustento de la oposición entre represión y prevención, oposición que puede ser entendida como invención estratégica por este tipo de discurso sociológico. Esta misma racionalidad puede encontrarse en la creación estratégica de la noción de solidaridad y de derecho social que Donzelot (2007) describe acerca de la invención de lo social' en Francia. De la misma manera que el conocimiento sociológico de Durkheim había ofrecido una útil herramienta con el concepto de solidaridad que en adelante sirvió como nuevo basamento de la Tercera República Francesa; el marcado enfoque de los intelectuales de Chicago por una mirada plenamente sociológica se enmarcó también en un plano estratégico acerca de las formas de dar respuesta a esa gran ciudad industrial transfigurada frente al "fracaso de los controles políticos y legales". Pero, además, consideramos que se entreteje una línea de fuerza que entiende 
a lo social a su vez como dimensión escindida y, en cierto modo, frente al Estado. Aquel rechazo a la concepción estado-céntrica europea, que Melossi (1995) vincularía a una 'tradición antiestatalista' norteamericana, se plasmó en la centralidad de las comunidades, en la participación de sus agentes, en la organización comunitaria, es decir, en la promoción de un desarrollo comunitario (Grondona, 2012), que será uno de los ejes fundamentales de sus propuestas preventivas.

La llamada Escuela de Chicago se caracterizó por su mirada 'ecológica', que, a partir de una reelaboración sociológica de la noción de 'patología' de las ciencias biológicas, utilizará como operador la idea de 'desorganización social' al referirse fundamentalmente a la ciudad como problema; luego, se observará una deriva más fuertemente 'culturalista' que resultará posteriormente en la teoría de la asociación diferencial de Edwin Sutherland (Sozzo, 2008b). Teniendo ante sus ojos la radical transformación de las ciudades norteamericanas, en la que urbanización, industrialización y fuertes corrientes migratorias internas y externas eran el caldo de cultivo y a la vez la consecuencia de profundas mutaciones políticas y culturales de aquella sociedad norteamericana (Melossi, 1995), la metáfora de la ecología, más que una aplicación estricta de dicha disciplina biológica, fue utilizada como fuente de inspiración para pensar a la ciudad como un 'hábitat' en el cual diferentes 'especies' se desarrollan siguiendo los cuatro procesos sociales básicos: competencia, conflicto, adaptación y asimilación (Park y Burgess, 1921; Melossi, 1995; Anitua, 2005; Sozzo, 2008b).

El concepto desde el cual este enfoque ecológico centrado en las 'zonas' se articulaba con los procesos económicos, sociales y culturales fue el de desorganización social o comunitaria. Así, Shaw y McKey negaban una relación directa entre la delincuencia juvenil y la pobreza sin la mediación de factores 'ecológicos', aun reconociendo que esta era de los rasgos fundamentales de las 'zonas de transición' y que esto dificultaba que las personas satisficieran sus necesidades por medios lícitos, haciendo una concesión a la teoría de la anomia de Merton (1968). A partir del concepto de desorganización social, intentaban dar cuenta de cómo en este espacio urbano no podía imponerse un patrón normativo eficaz, dada la pobreza, pero también la altísima heterogeneidad cultural y la debilidad institucional. Los diferentes grupos de inmigrantes se encontraban en 'conflicto' entre sí y, a la vez, con la cultura norteamericana dominante, situación que explicaba 
la imposibilidad del establecimiento de un patrón cultural homogéneo. En su perspectiva, este conflicto cultural se conjugaba con problemas ligados a las condiciones de vida y al trabajo: la pobreza obligaba a largas jornadas de trabajo de los padres que perdían la posibilidad de controlar y educar a sus hijos, argumento que también habíamos registrado en Ferri (Cid Moliné y Larrauri Pijoan, 2001; Anitua, 2005; Sozzo, 2008b).

Luego de esta breve introducción sobre la corriente sociológica en la cual abreva Thrasher, nos referiremos a su texto de 1933, "La delincuencia juvenil y la prevención del delito" (2010). Como analizamos en la teoría de los equivalentes de las penas de Ferri, también Thrasher se inscribe en una retórica sobre la prevención del delito que la entiende como una tarea en vacancia, como emprendimiento que ha sido descuidado por las intervenciones de política criminal, con la particular importancia que este descuido ha implicado el descentramiento de la intervención sobre las verdaderas 'causas' de los comportamientos delictivos y no solo en sus manifestaciones exteriores o finales. Propone una mirada 'ilustrada', que analiza, diagnostica y prescribe, frente al automatismo con que son caracterizadas las respuestas penales:

La creciente gravedad del problema del delito en los Estados Unidos ha focalizado ocasionalmente la atención del público ilustrado sobre la posibilidad de un ataque más sustancial y sistemático a las causas subyacentes del delito que el que se había intentado hasta ahora [...]. El terreno para este tipo de ataque ha sido preparado a través de la adquisición de importantes conocimientos sobre los orígenes del delito, que están disponibles gracias a recientes estudios científicos que señalan, por un lado, que los orígenes de las carreras delictivas se encuentran en las reacciones sociales de la niñez y la adolescencia y, por otro, que la concentración de delincuentes y criminales se encuentra en áreas típicas, intersticiales, que son los lugares característicos de generación de las pandillas juveniles, la delincuencia y el crimen (Thrasher, 2010, p. 111).

Esta perspectiva científica es reconstruida en Thrasher desde dos ejes que son reelaborados y jerarquizados en comparación con la sociología de Ferri: la cuestión de la juventud y la ciudad o lo urbano. Estos dos ejes son presentados como 'dos significativas generalizaciones', las cuales, a partir de comprobaciones objetivas, muestran que el punto de ataque de una 
intervención de prevención del delito son los problemas de conducta en la infancia y la adolescencia, y el mal funcionamiento de las instituciones sociales en las 'áreas de producción del delito'. La presentación de la forma necesaria de intervención sobre estas problemáticas es organizada a través de la noción de desorganización social, que, como vimos, es cara a la producción de la Escuela de Chicago. Se argumenta que el trabajo es lidiar con las influencias sociales que afectan a los 'predelincuentes' o 'potenciales delincuentes' en las 'áreas de deterioro' urbano, intentando asegurar "el desarrollo integral de la personalidad y la buena ciudadanía". En este contexto, se construye la idea de una integralidad de la acción, en el sentido de la necesidad de poner en marcha una serie de diversas técnicas y procesos que intervengan de manera 'completa' en la situación 'total' de un área de delincuencia: "un minucioso programa de planificación social" (Thrasher, 2010, p. 112).

Thrasher, retomando la centralidad de la dimensión local o comunitaria, sostiene que 'la pandilla' (traducción de la expresión the gang, que además es el título de su obra más importante, de 1927) es un síntoma de 'desorganización comunitaria', que juega un rol importante en la 'desmoralización de la juventud' en estas áreas intersticiales. Así, el análisis y la problematización de lo urbano que caracterizó la producción intelectual de la Escuela de Chicago centrado en la idea de desorganización son retomados por Thrasher como eje de tematización de lo comunitario en tanto uno de los principios rectores de los programas de prevención del delito. Lo local-comunitario y la juventud se construyen en líneas rectoras que convergen en la noción de desorganización comunitaria. En esa línea, plantea que las conclusiones de diferentes estudios recientes de su autoría y de otros investigadores (Shaw, Lundesco, Shulman y Glueck) indican los elementos esenciales de un plan de prevención del delito para la comunidad local. Los organiza en dos dimensiones, los objetivos y los medios para alcanzarlos.

Aquí Thrasher plantea entonces, en primer lugar, la cuestión de la integralidad, es decir, esta idea de prevención del delito como un programa social amplio y comprehensivo que bajo su dirección organice todas las 'agencias' comunitarias. Pero la idea de integralidad en tanto cooperación entre agencias locales no alcanza a la cuestión de los destinatarios de la política: si bien plantea la idea de incorporar al programa a todos los niños residentes en esas áreas 'de delincuencia', tiene el objetivo de una minuciosa 
tarea de evaluación, para conservar dentro del dispositivo a la 'minoría' de los 'potenciales delincuentes'. En primer lugar, observamos una segmentación territorial: el primer paso es la definición del territorio específico por intervenir; es necesario definir las áreas en términos de la noción de espacios de 'desorganización social' o áreas de delincuencia, que, en el caso del trabajo de Thrasher, lo recomienda a partir de los textos de C. Shaw (1930; Shaw y McKay, 1942). En segundo lugar, hay un recorte que pretende identificar y enfocar el trabajo preventivo en los 'potenciales delincuentes'.

Este objetivo hace eje en incorporar a estos niños a actividades y organizaciones que se vinculen a las necesidades, con especial referencia a las lúdicas y al tiempo libre. En este sentido, la prevención del delito se expresa como un intento de 'organizar' lo desorganizado, es decir, organizar y programar las actividades de los destinatarios a partir de la canalización de las 'necesidades normales' para evitar las actividades patológicas, como la formación de 'pandillas', propias de la desorganización comunitaria. Esta tarea de organización comunitaria como trabajo preventivo se encuentra impregnada de la preocupación por el fomento a la participación de las agencias y los habitantes de dichas zonas, entendiendo la estrategia preventiva como modalidad de desarrollo comunitario que pretende generar una activación de las instituciones comunitarias en tanto responsabilización. Por ello, al listar los medios que debe utilizar un programa preventivo, el primero indicado dice: "Concentración de la responsabilidad para la prevención del delito en el área de delincuencia local en cuestión". Esta orientación, también caracterizaba al programa preventivo Chicago Area Project, dirigido por Shaw (Medina Ariza, 2010; Ayos, 2013a). Es decir, muestra una mirada común de los sociólogos de Chicago sobre las capacidades preventivas de la organización social en tanto desarrollo comunitario que interpele y tenga como protagonistas a los propios sujetos e instituciones. Esta impronta del desarrollo comunitario es una de las líneas de fuerza que con más intensidad observamos reelaborarse en las políticas preventivas en la actualidad, aunque, por supuesto, las particularidades históricas con las que esta forma de problematización se reactualiza muestra distintas vertientes y modalidades que hemos analizado en nuestro trabajo de investigación (Ayos, 2012a, 2013a).

En estos elementos, encontramos fuertes distancias con la teoría de los equivalentes de las penas de Ferri, comparándolos en los ejes temáticos 
que han organizado nuestra investigación: el lugar de la política social y la intervención sobre las condiciones de vida; la elaboración de la población objetivo; y los modos de territorialización. En principio, como ya mencionamos, la dimensión espacial, vinculada a la cuestión de las áreas urbanas específicamente criminógenas, que en Ferri no era problematizado: como dijimos, su 'territorio' era la sociedad industrial capitalista. Pero, por otro lado, aparece la cuestión de la 'organización' de las actividades y las conductas de los 'niños', que, en última instancia, está vinculada a la producción de ciertos patrones culturales opuestos a la cultura de la pandilla (como cultura emergente de la desorganización comunitaria), que en Ferri tienen un lugar menor (recordemos su menosprecio a las campañas moralizadoras en relación con el alcoholismo y sus reparos a la dimensión educativa de los equivalentes de las penas) frente a la 'elevación de la vida popular' desde su concepción materialista.

Volviendo al trabajo de Thrasher, este expone la formulación concreta de un plan de prevención. En cuanto a su organización, destaca dos ejes. En el primero, hace referencia a la forma en que debe presentarse la intervención en la comunidad: recomienda explícitamente evitar la denominación de 'prevención del delito', debiendo ser conocido como 'sección ciudadana' o 'programa de ciudadanía', expresando lo problemático de los vínculos entre la prevención del delito y las intervenciones sociales. El segundo eje vuelve sobre la integralidad: subraya que debe componerse por representantes de diversas agencias sociales, cuya cooperación es esencial. Y aquí también es importante observar cómo la 'multiagencialidad' es no solo un eje contemporáneo, sino una cuestión constitutiva del campo de la prevención del delito que es reactualizado de diferentes formas: a partir de mediados de los años setenta, el llamamiento a la participación de diferentes agencias, especialmente las 'comunitarias' o de la 'sociedad civil', se inscribe en el marco de la emergencia de la matriz de la 'seguridad' en el campo del control del delito, pero como parte del movimiento más general del redescubrimiento neoliberal de la sociedad civil.

En cuanto a su alcance, establece que, siguiendo los lineamientos ya expuestos, el programa debe concentrarse en determinadas áreas o áreas caracterizadas por los altos índices de delincuencia. Los primeros pasos deben considerarse 'exploratorios y experimentales': este es un elemento fuertemente retomado en las políticas de prevención actuales en Argentina, 
a partir de la noción de 'inserción comunitaria' en la delimitación de las 'zonas' de intervención (Ayos, 2011, 2012a, 2013a).

A su vez, Thrasher desarrolla las diferentes funciones que debe realizar el programa, las cuales condensamos en dos líneas. La primera refiere a las funciones de investigación y sistematización de la información. Aquí destaca el papel de la investigación social como base para las intervenciones de prevención del delito: no en la forma de la 'superficial' encuesta de las agencias sociales, sino con la profundidad y sistematización de la investigación científica. Nos encontramos nuevamente con una racionalidad científico-técnica que marca la impronta de la concepción entre conocimiento-política.

La segunda función es la de los servicios integrados y del trabajo social. En primer lugar, define más específicamente a la población destinataria del programa: a) niños y jóvenes, tanto en términos individuales como grupales (la idea ya mencionada de gang o pandilla) que no están incorporados a las 'estructuras sociales' convencionales, entendidas como las instituciones o agencias estatales comunitarias; b) niños que sí se encuentran incluidos (especialmente en la escuela) pero que tienen 'problemas' fuera de esta; c) niños que no asisten a la escuela y en situación de 'desempleo' o empleados que muestren problemas de 'adaptación'. Por otro lado, destaca el papel del trabajo social como orientado sobre casos 'especializados y difíciles', y la organización de dispositivos nuevos para afrontar procesos que no tratan las agencias existentes. Pero es significativo remarcar que Thrasher se plantea la cuestión de las continuidades y las diferencias entre esta intervención de prevención del delito y el 'trabajo social': nos dice que la prevención del delito utiliza 'técnicas subsidiarias' (clínica de la conducta, trabajo social con las familias, recreación, educación) del trabajo social, pero la diferencia su organización en una programación comunitaria integral basada en los resultados y conclusiones de la investigación social. La prevención del delito se distingue entonces del trabajo social en la integralidad de la primera, derivada de la racionalidad científico-técnica que la conduce, en comparación con la fragmentación y dispersión vinculada al trabajo social. En algunos pasajes, esa racionalidad ligada a la ciencia se pone en contacto con una noción de economía. La idea de 'ir a la raíz' expresa una racionalidad científico-técnica que muestra la 'verdadera naturaleza' de los procesos sociales, pero también una racionalidad instrumental económica, en el sentido de ser la forma más económica, eficiente de resolver la cuestión. 
En el análisis del trabajo de Thrasher, pudimos observar, en línea de continuidad con la teoría de los equivalentes de las penas de Ferri, un discurso que reconstruye la oposición entre represión y prevención a partir de una línea ético-política progresista (ya no es el socialismo evolucionista, sino el enfoque 'democrático radial' del que hablaba Melossi) y una dimensión científico-técnica centrada en el conocimiento sociológico de las causas del delito que justifica las medidas preventivas en términos de eficacia, racionalidad y economía de acción. Sin embargo, son construcciones conceptuales con profundas y significativas heterogeneidades: por un lado, la cuestión de la 'escala', es decir, la ciudad y los espacios urbanos locales o comunitarios como problema específico. Además, marca un quiebre con Ferri la relevancia de la dimensión cultural en los procesos de prevención, como emergente de los intercambios comunitarios en las 'áreas de delincuencia'. Esta dimensión permite entender, por ejemplo, a la "pandilla como un síntoma de la desorganización comunitaria" (Thrasher, 2010, p. 112). En tercer lugar, la propuesta preventiva en tanto intento de re-organización comunitaria se asienta en una estrategia de responsabilización de los propios agentes y habitantes comunitarios. Como ya adelantamos, entendemos que este eje plantea una forma de problematización de lo 'social', como apertura de un espacio de intervención que en nuestro caso se construye a partir de la oposición entre represión y prevención, que hace hincapié en su dimensión 'no estatal', y, en cierto sentido, 'frente' al Estado. Esto la aleja de la problematización de Ferri, que centraba su reforma en el ámbito legislativo. Si bien la idea de una respuesta integral a partir de la intervención en múltiples ámbitos como forma preventiva ya se encuentra en Ferri, la idea de la coordinación de diferentes 'agencias' sociales en el espacio local no se encontraba en el autor italiano. La idea misma de 'programa' de prevención es ajena a Ferri, quien, como vimos, recurre a la metáfora de un 'código preventivo' en oposición al Código Penal. Esta idea de 'programa' se enraíza en la concepción de desarrollo comunitario que delimita poblaciones y objetivos específicos, y no en los términos generales y extendidos que presentaba Ferri, refiriendo a la seguridad social.

Estos distintos elementos de continuidad y ruptura que moldean la mirada de la Escuela de Chicago sobre la prevención del delito con respecto a Ferri nos interesan en tanto van delimitando ciertas formas de problematización que entendemos significativas para dar cuenta de las experiencias 
históricas de prevención en Argentina. Nos referimos en particular a una articulación que atraviesa estas políticas entre un posicionamiento que intenta introducir una mirada 'social' en el interior de la política criminal (frente a las propuestas neoconservadoras de 'tolerancia cero') y una recuperación de las derivas fundamentales de la reforma neoliberal de la política social en Argentina: la línea asistencial-laboral o tipo workfare y la centralidad de lo comunitario (Ayos, 2011, 2012b, 2013b).

De la misma manera, en el apartado siguiente, identificaremos las continuidades y rupturas que presenta el Realismo de Izquierda en relación con las formulaciones que hemos analizado hasta aquí, como forma de 'llegada' a uno de los enfoques que también nos interesa por el caso argentino. Anticipándonos a la última sección de este artículo, diremos, sin embargo, que, aunque entendemos que estas tres construcciones diferentes en el conocimiento criminológico son organizadoras de las formas en que la prevención social del delito ha sido desarrollada, precisamente, en Argentina, creemos que existen varios 'eslabones perdidos' entre la mirada 'de Chicago', tal como la presentamos aquí, y el Realismo de Izquierda. El de mayor envergadura es, por cierto, el análisis funcionalista de Robert Merton (1938), centrado en la noción de anomia en tanto producto de la tensión estructural entre medios y fines. La idea central del planteo mertoniano entiende al delito como comportamiento anómico, resultado de la tensión entre la estructura social (atravesada por la desigualdad en el acceso de oportunidades) y la estructura cultural, caracterizada por un desequilibrio en la ponderación de los medios y los fines. En su análisis, Merton señala que la sociedad norteamericana es anómica, en primer lugar, porque su estructura cultural se encuentra desbalanceada, en tanto ejerce una presión muy fuerte, casi excluyente, sobre los fines ligados al éxito económico individual y otra muy débil en relación con los medios legítimos, institucionalmente prescriptos, para alcanzarlos. A su vez, se observa un 'universalismo' con respecto al mandato cultural del 'sueño americano': no importa el origen social, todo individuo debe buscarlo. Si esta estructura cultural se conjuga con una estructura social signada por la desigualdad, se produce una presión estructural hacia la anomia y la adopción de patrones de conducta que utilizan medios ilegítimos (Merton, 1938, 1968; Cambiasso y Grieco y Bavio, 1999; Cid Moliné et al., 2001; Anitua, 2005). 
Como veremos en el próximo apartado, el Realismo de Izquierda, y en particular Jock Young, recuperó a Merton en el sentido de entender al delito como producto de tensiones estructurales, pero planteando la necesidad de incorporar la dimensión cultural: de ahí el título de su artículo "Merton con energía, Katz con estructura" (2008). Si bien, para referir a la dimensión cultural, Young, ya en la década de los noventa, trae a Jack Katz, autor del influyente Seductions of crime (1990); la dimensión cultural en el análisis de la cuestión criminal tiene una historia que se remonta, como vimos, a la producción de la Escuela de Chicago, profundizada en su deriva propiamente 'culturalista', expresada paradigmáticamente en los trabajos de Edwin Sutherland y su teoría de la 'asociación diferencial'. En términos muy escuetos, podemos decir que este autor propone entender al delito como un comportamiento que, como cualquier otro, es aprendido en un proceso de interacción basado en la comunicación social. En este sentido, Sutherland sostiene que "una persona se convierte en delincuente porque en su medio hay un exceso de definiciones favorables a infringir la ley, en tanto que permanece aislada o inmunizada respecto de grupos que mantienen definiciones favorables a respetar la ley. Este es el principio de asociación diferencial" (Sutherland, 1947, p. 88, citado en Cid Moliné et al., 2001, p. 101). Si en principio, para dar cuenta de las formas diferenciales en que se producían los delitos en diversos lugares, este autor recogió la noción de desorganización social de sus colegas de Chicago, luego utilizará la noción de organización social diferencial, dado que esas definiciones culturales eran el producto de una aceitada organización más que de su falta (Cambiasso et al., 1999; Cid Moliné et al., 2001).

Los intentos de complementar los análisis de Merton sobre la presión anómica estructural y la mirada que abre Sutherland en relación con entender el delito como comportamiento aprendido, como producto cultural, se plasmarán en las teorías de las 'subculturas', fundamentalmente en Albert Cohen (1955) y Richard Cloward, junto a Lloyd Ohlin (1960) (Cid Moliné et al., 2001; Anitua, 2005; Medina Ariza, 2010). Nos interesa la posición de Cloward y Ohlin porque, a partir de su teoría y con la dirección del propio Ohlin, se puso en marcha uno de los programas de prevención del delito que podemos entender como 'excepciones' de experiencias extrapenales antes del 'giro preventivo' de los años setenta y ochenta: el programa Movilization for Youth en la ciudad de Nueva York, el cual recuperaba el 
enfoque de desarrollo comunitario que presentaba el Chicago Area Project (Ayos, 2013a). Estos autores sostenían que no solo la presión anómica incide en la adopción de conductas ilícitas, dado que no es suficiente con tener las oportunidades lícitas bloqueadas, sino que es necesario tener a disposición y aprender a utilizar los medios ilícitos (Cloward y Ohlin, 1960; Cid Moliné et al., 2001; Anitua, 2005; Medina Ariza, 2010). Esto abre la mirada sobre el proceso de producción de subculturas criminales como espacio de aprendizaje de estos repertorios ilícitos y abre, a su vez, la posibilidad a las estrategias preventivas de desarrollo comunitario, retomando la experiencia de Chicago, que se inscriben en la 'guerra contra la pobreza' de los gobiernos demócratas norteamericanos de la década de 1960. El Realismo de Izquierda va a retomar la noción de subcultura en un diálogo (crítico) con estas conceptualizaciones.

\subsection{Lea, Matthews y Young y el Realismo de Izquierda}

Para introducir los debates y conceptualizaciones que el Realismo de Izquierda trae al campo de los estudios sobre el delito y la pena, seguiremos fundamentalmente algunos lineamientos que contiene el libro ¿Qué hacer con la ley y el orden? de John Lea y Jock Young (2008), publicado por primera vez en 1984. Luego, para referirnos específicamente a la problemática de la prevención del delito, analizaremos el trabajo de John Lea, Roger Matthews y Jock Young, "El Estado y el control del delito: enfoques relativos a la actividad diversificada de sus agencias" (1993).

La corriente criminológica que ha dado en llamarse y se ha conocido como el 'realismo criminológico de izquierda' sitúa su propio surgimiento a principios de los años ochenta como reacción tanto a las corrientes criminológicas "cada vez más represivas" de derecha como a lo que llaman un 'idealismo' criminológico de izquierda. Este surgimiento lo enmarcan en el auge neoliberal de control punitivo y colapso de las viejas criminologías liberales y socialdemócratas (las que entraron en crisis por establecer una relación directa y mecánica entre delito y pobreza, según los autores). La 'nueva derecha' de fines de los setenta y principios de los ochenta, neoconservadora y neoliberal, abandonó los factores sociales como explicación de los fenómenos delictivos, pasando al frente las características biológicas y psicológicas de los individuos. Así, presentan la tendencia a entender al 
delincuente como una persona que calculaba 'racionalmente' los costos y beneficios del acto delictivo; se conjuga con esto el abandono de la idea de 'rehabilitación social' del delincuente y un retorno al sistema de justicia criminal represiva como orientación disuasiva. Por último, una invocación al deterioro de la 'moralidad' como causa de la criminalidad (Lea y Young, 2008).

Sobre esta situación, los autores critican la reacción de las corrientes de izquierda, ya que, según ellos, en gran medida reflejó a las de derecha: a la mirada del delincuente como sujeto moralmente condenable, se opuso la idea romántica del delincuente como rebelde del orden social. A su vez, cuestionan cierta 'evitación': algunas posturas evitaron la cuestión del delito en sí mismo, a partir de la interpretación de la cuestión de la criminalidad en tanto distractor de la nueva derecha neoliberal sobre los verdaderos problemas sociales que se vislumbraban: la desocupación y la creciente desigualdad (Lea et al., 2008).

Los autores plantean que la ausencia de un discurso de izquierda que "tomara en serio al delito", es decir, que visualizara "los efectos perjudiciales del delito en sus víctimas, principalmente los pobres y los débiles" (Lea et al., 2008, p. 2) abrió el camino a los neoliberales y conservadores, al ser los únicos interlocutores sobre dicha cuestión. Sobre este vacío, plantean el problema de construir una criminología 'firmemente radical'.

Así, ubican las causas del delito en las estructuras materiales y simbólicas del capitalismo moderno, lo entienden como fenómeno 'normal' y, a la vez, real. E introducen la noción de privación relativa, desmarcándose de las posiciones que vinculan directamente delito y pobreza, introduciendo la cuestión de las percepciones sobre las distancias sociales y las expectativas subjetivas como explicativas de los niveles de delincuencia. Esta dimensión simbólica y cultural es central dentro de la corriente y será profundizada en trabajos posteriores, especialmente por Young en artículos como el ya mencionado, "Merton con energía, Katz con estructura. La sociología del revanchismo y la criminología de la transgresión" (2008), "Canibalismo y bulimia: patrones de control social en la modernidad tardía" (2001) y en su libro La sociedad excluyente (2003), al analizar cómo los patrones culturales del sueño americano son reconstruidos en las prácticas delictivas de los jóvenes de las clases populares norteamericanas, cimentando la reproducción de su posición de clase subalterna, retomando los análisis de Paul 
Willis (1997) sobre los jóvenes estudiantes ingleses. Desde aquí se critica la mirada romántica del delincuente como rebelde contra el capitalismo: "Es más bien una de las maneras en que el sistema capitalista se perpetua a sí mismo al crear división y agresión y al inculcar en los pobres la ambición y el egoísmo de los ricos" (Lea et al., 2008, p. 3). En este punto, introducen la noción de subculturas, en una definición en la que también se observa la influencia de la hipótesis mertoniana de la tensión estructural:

Las subculturas son mecanismos de resolución de problemas que surgen constantemente mientras que las personas que pertenecen a grupos específicos intentan resolver los problemas estructurales que sufren. [...] El delito es una forma de adaptación subcultural que ocurre cuando las circunstancias materiales obstruyen las aspiraciones culturales y donde las alternativas que no implican la comisión de delitos no existen o resultan menos atractivas (Lea et al., 2008, p. 14).

En un intento de superar la parcialidad de las corrientes criminológicas anteriores, las que hacían hincapié en el comportamiento del delincuente o en la reacción social al ilegalismo, y entendiendo que la realidad del delito se compone, necesariamente, de normas y personas que las violan, los realistas de izquierda proponen descomponer la naturaleza del delito en su forma, su contexto social y su dimensión temporal, es decir, en los diferentes momentos en los que este transcurre. La forma del delito estará dada por lo que los autores llaman el 'cuadrado del delito', formado por dos binomios: víctima y delincuente, y acciones y reacciones (tanto informal como formal a partir de los organismos estatales de justicia criminal). Es decir, la naturaleza del delito está dada por la forma en que se establezcan las diferentes articulaciones entre estos elementos que delimitan el 'cuadrado del delito'. En segundo lugar, el contexto social del delito refiere tanto a los procesos de interacción social inmediata de aquellos cuatro elementos como a su ubicación en la estructura social. Por último, el aspecto temporal del delito es descrito como el pasado de cada uno de los cuatro elementos mencionados y el impacto de cada uno en el futuro, descomponiendo en las causas mediatas e inmediatas del comportamiento criminal y de las formas de la reacción, la situación y la respuesta frente a la víctima, a saber: 1) las causas anteriores a la comisión del delito; 2) el contexto moral en el que se 
opta por el comportamiento criminal; 3) la situación en la que se comete el delito; 4) la detección del delito; 5) la respuesta frente al delincuente; y 6) la respuesta frente a la víctima (Lea et al., 2008; Bergali, 2003; Matthews y Young, 1993).

Ya entrando en el campo más programático, hay una fuerte apuesta al papel del conocimiento sociológico en la construcción de intervenciones que logren perforar la barrera del nothing works en materia de política criminal. Investigación, diseño de políticas, supervisión y evaluación son los componentes de un nuevo vínculo entre conocimiento y práctica de gestión pública. Por otro lado, plantean la cuestión de la necesidad de intervención 'en todos los niveles' al mismo tiempo que plantean la 'prioridad' de lo social sobre el sistema de justicia criminal en cuanto al control de delito. Contra el exagerado papel que la doctrina tradicional asigna a la policía y su papel represivo, sostienen: "No es la 'delgada línea azul' [la policía], sino los ladrillos y el cemento de la sociedad civil los que constituyen nuestra mayor protección frente al delito. Buenos empleos con futuro, barrios municipales que sean el orgullo de sus habitantes, instituciones que aumenten el sentido de cohesión y pertenencia, reducción en la distribución desigual de los ingresos, todo eso crea una sociedad que es más cohesiva y menos criminógena" (Lea et al., 2008, p. 16).

Proponen intervenir inmediatamente, criticando las posiciones de izquierda que creen que nada puede hacerse ante la percepción de la imposibilidad de hacer transformaciones profundas: son centrales las reformas sociales inmediatas, más si estas se expresan en términos de objetivos de justicia social a largo plazo. También es importante destacar que advierten contra las formas de la nueva tendencia actuarial y administrativa de control del delito, que vinculan a las formas de prevención situacional, como así también contra las políticas 'nostálgicas' conservadoras acerca del fortalecimiento de la familia y la comunidad (Lea et al., 2008).

La relevancia del conocimiento científico-técnico, en particular la investigación sociológica, se conjuga con un reformismo socialdemócrata como orientación ético-política, que retoma la oposición entre represión y prevención que habilita un espacio de intervención 'social'. Pero la forma en que es tematizado este espacio de intervención 'social' muestra cierto rasgo de época: "Los ladrillos y el cemento de la sociedad civil" son la verdadera protección contra el delito; la participación de los habitantes y de 
las instituciones comunitarias es, como veremos, parte de una estrategia que pretende ser defensiva frente a la intervención estatal centrada en la policía. En este sentido, entendemos que se recupera (con múltiples diferencias) aquella tradición 'antiestatal' que señalamos en la producción de la Escuela de Chicago.

El artículo de Lea, Matthews y Young, "El Estado y el control del delito: enfoques relativos a la actividad diversificada de sus agencias" (1993), comienza con un intento de historización de dos elementos que atraviesan el campo del control del delito a partir de los años ochenta: el llamamiento a una mayor cooperación entre diferentes agencias estatales y a una participación más amplia de diferentes actores en el proceso de toma de decisión y desarrollo de un política pública. En el campo específico de la política criminal, el aumento de la preocupación por el delito durante las décadas de los setenta y ochenta ejerció una presión para que las agencias pertinentes tuvieran que trabajar en niveles de coordinación mayor. Bajo un diagnóstico de crisis de eficacia de las políticas de control del delito (que los autores aceptan), que incluía un aumento vertiginoso de las tasas de criminalidad, de la población carcelaria y de la reincidencia, así como la disminución de esclarecimientos, y en un clima de desilusión sobre las posibilidades de resolución mediante la expansión del aparato administrativo existente, se observaron tendencias hacia la privatización y la mayor cooperación entre las agencias estatales. Los autores sostienen que la privatización es una opción acotada en el ámbito de la justicia criminal, por la necesidad del Estado de mantener la responsabilidad total en la materia; la cooperación estatal se mostró como una alternativa para extender las prácticas y los conocimientos técnicos existentes. Sin embargo, como hemos analizado en el apartado anterior, la privatización de diferentes ámbitos fue una característica saliente de la reorientación contemporánea de la política criminal en Inglaterra y los Estados Unidos, a partir de la proliferación de un mercado de servicios de 'seguridad', como la vigilancia privada o los seguros contra robos.

Como expresión de este proceso, se refieren al que califican como influyente informe del Home Office (Ministerio del Interior británico) titulado Crime reduction, que hace hincapié en la necesidad de coordinar esfuerzos en cuanto a la prevención del delito, como también en la de ampliar la base de toma de decisiones de las políticas de control del delito. Sus fundamentos 
refieren, en primer lugar, a las evidencias empíricas que indicaban que la efectividad policial no provenía del incremento de la mano de obra policial o del aumento de la tecnología. Segundo, que la no cooperación de alguna de las agencias implicada era capaz de hacer fracasar cualquier intervención. Tercero, un porcentaje significativo de la población que tenía contacto con el sistema de justicia criminal sufría una serie de "problemas (vivienda, trabajo, problemas personales) y estaba, por lo tanto, sujeta a diferentes formas de intervención" sin coordinación alguna, lo que reducía su efectividad. Cuarto, reconoce que el problema del delito varía considerablemente según su dimensión local. Por último, señala que un efectivo control de la criminalidad depende de la participación pública y del flujo de información hacia las agencias policiales que de ella se eleva. Lo local y la participación son retomados en términos de la 'comunidad', como instancia fundamental para este nuevo diagnóstico: "Así, la comunidad pasaba a ser vista como una de las agencias con la que deberían hacerse alianzas. En realidad, era vista no sólo como el factor clave en la formulación del problema de la criminalidad, sino también de su resolución" (Lea, Matthews y Young, 1993, p. 22).

Aquí nos interesa destacar la forma en que los autores retoman la cuestión de la multiagencialidad y su relación con el aumento de la eficiencia de la intervención estatal, que ya era planteada en la problematización de la integralidad en la prevención del delito, la cual, como vimos, realizaba Thrasher en 1933, retomando el enfoque de la articulación de agencias en el ámbito local; mirada ajena a Ferri y su perspectiva macrosocial. Pero la reivindicación de la multiagencialidad en los realistas de izquierda se produce en un contexto distinto, en el que las orientaciones neoliberales, en su crítica a los arreglos welfaristas, promueven nuevos criterios de eficiencia ligados a la cooperación entre diferentes ámbitos estatales bajo argumentos de restricción fiscal. De esta manera, podemos interpretar la reivindicación de la multiagencialidad que se produce en los años ochenta como el cruce de dos líneas: la idea de cooperación entre agencias, propia del campo de la prevención del delito, cuya historia se remite a las primeras décadas del siglo XX (como observamos en las propuestas de Chicago), y la corriente neoliberal de reforma del Estado.

En términos generales, la propuesta de coordinación multiagencial que presentan los autores plantea una relación entre el campo de las políticas 
criminales y el campo de las políticas sociales que aparece como no problemática. Las formas de articulación entre la policía y la justicia y las agencias 'sociales', siempre en la 'escala' de las comunidades, son reconstruidas como intentos de aumentar el grado de eficiencia con las que estas instituciones impactan sobre las comunidades, respondiendo a sus necesidades, en un proceso de indistinción entre dichos campos. En este sentido, la multiagencialidad es entendida como forma de hacer más eficiente la intervención estatal, introduciendo una racionalidad científico-técnica, pero también, y al mismo tiempo, como modo de atender las problemáticas de las comunidades más desfavorecidas, en un posicionamiento ético-político progresista. La recuperación de la preocupación por las 'causas sociales' del delito que identifica la investigación sociológica aparece aquí como 'ampliación' del control del delito, incluyendo a las agencias 'sociales' como clave de una respuesta socialdemócrata al problema del delito, como alternativa a la respuesta policial.

Los autores sostienen que la perniciosa hegemonía de la institución policial en el campo de la política criminal eclipsa la importancia que tienen otras instituciones en los procesos de control social, subrayando el papel de instituciones como la escuela y la familia. Así, la propuesta multiagencial pretende valorar y recuperar las funciones de control social que portan estas instituciones sobre los adolescentes y jóvenes en un trabajo de coordinación con las agencias policiales en términos de control del delito.

... una muy alta proporción de lo que está convencionalmente definido como delito y desórdenes son, en realidad, cometidos por adolescentes que provienen de escuelas y de familias. En verdad, estas son las dos instituciones sociales que signan sus vidas de manera más marcada. Cuando se advierte esta situación, surge una pregunta espontánea, cual es: ¿cómo se coordinan conjuntamente estas instituciones en términos de control del delito (por ej. la policía, la escuela y la familia)? La respuesta a esta pregunta es, por supuesto, que, aunque el control social es de facto ejercido por una pluralidad de agencias, no hay ninguna noción coherente de su coordinación, y no digamos ya una distribución planeada de los recursos (Lea et al., 1993, p. 30).

Sin embargo, lo que se observa en este planteo es un pasaje desde la noción de control del delito hacia la noción de control social: es criticada la 
centralidad de la policía en el sentido de sostener que su papel es pequeño frente a instituciones como la familia o la escuela en los procesos de control social. Ahora bien, este desplazamiento se produce sin mediaciones, de manera que instituciones como la escuela y la familia quedan naturalmente vinculadas al control del delito, asimilándolo a los procesos más generales de regulación, formación o control. Es oportuno destacar que, si bien esta indiferenciación entre control del delito (y el consiguiente accionar de las agencias del sistema penal como la policía) y control social (vinculado a las intervenciones sociales) se desprende de su problematización de la multiagencialidad, también ella contiene un discurso a favor de la restricción de la actividad policial al control del delito específicamente, restricción a su participación en solo ciertas etapas del proceso de justicia criminal: "Sólo aquellos limitados momentos y ocasiones donde la fuerza coactiva resulta necesaria: todo lo demás es trabajo social" (Lea et al., 1993, p. 56).

Esta forma de problematización de la prevención del delito, en tanto intervención multiagencial que insta a un proceso de cooperación de las instituciones del sistema penal con agencias sociales locales y que opera un deslizamiento desde el control estatal del delito hacia la noción más general de control social, se presenta también como una interpelación tendiente a la mayor participación de las comunidades en la cuestión del delito. Es decir, es retomada la retórica de la participación, la activación de las energías comunitarias, en la cual sus habitantes y sus instituciones son llamadas a tener un mayor protagonismo en la administración del delito: "Donde las autoridades locales, la policía y la población han trabajado de manera mancomunada, ha habido considerables resultados" (Lea et al., 1993, p. 28). La revitalización de las instancias comunitarias de participación aparece como un límite, como límite comunitario, a la intervención estatal hegemonizada por la policía. Aunque en el contexto de una estrategia 'defensiva' y socialdemócrata, ante la centralidad de la intervención policial, esta retórica puede leerse en términos de una responsabilización de la comunidad en el ámbito del control del delito. Rasgo que no es ajeno a tendencias más generales de la reorientación del campo de la política criminal contemporánea. La cita del jefe de Policía, Sir Kenneth Newman, declarando en el Strategy Statement su compromiso con el enfoque 'multiagencial' repone esta retórica de una comunidad responsabilizada, donde residen los principales recursos para la reducción del delito. 
De este modo, el Realismo de Izquierda reconstruye una mirada sobre la prevención del delito que conjuga la cuestión de una multiagencialidad en tanto incorporación de agencias sociales para disputar la hegemonía policial en el control del delito (operando un deslizamiento hacia la idea más general de control social), con una interpelación a la comunidad, una activación de sus instituciones y habitantes, otorgándoles un rol destacado en esta tarea. Esta problematización muestra fuertes continuidades con la Escuela de Chicago en relación con la 'escala' local que la atraviesa, en tanto espacio donde es posible la coordinación multiagencial. Por otro lado, la propuesta de los realistas de izquierda retoma la impronta de desarrollo comunitario que caracterizó a la problematización de los intelectuales de Chicago. Por supuesto, es diferente el campo de adversidades del cual emerge: la racionalidad neoliberal y su crítica del Estado; la 'nueva derecha' criminológica en sus vertientes actuariales y punitivas, con la preponderancia del accionar policial; y las criminologías denostadas por los realistas como 'idealistas'. Por otra parte, los realistas retoman el énfasis de Ferri en los procesos socioeconómicos que estructuran a las sociedades modernas capitalistas, en especial las condiciones de vida de las clases populares, aunque siempre distanciándose de posiciones mecanicistas en cuanto a la relación entre delito y pobreza, introduciendo la noción de cultura. Y, en este punto, también podemos encontrar las reminiscencias de los sociólogos de Chicago, aunque con salvedades, que es necesario señalar. Los realistas de izquierda realizan una fuerte crítica a la perspectiva 'ecológica' de Chicago: entienden que esta teoría recupera el 'legado positivista' en sus metáforas naturalistas, asimilando "patrones culturales y zonas naturales" (Taylor, Walton y Young, 2007, p. 137). Esta crítica a la mirada que cruza territorios y cultura es la que abre la puerta a la idea de cultura como emergente de tensiones estructurales. Sin querer cancelar estas significativas diferencias, y también señalando que la noción de cultura como producto de tensiones estructurales no es absolutamente ajena a la sociología de Chicago (recordemos que el contexto de su producción son las mutaciones de las urbes norteamericanas de principios de siglo), creemos que la dimensión comunitaria de sus propuestas preventivas es el hilo conductor que morigera esta revisión sobre la sociología de Chicago. La recuperación en la dimensión cultural de su perspectiva y la 'escala' comunitaria de su programática política es subsidiaria de aquella forma de problematización, 
ambos ejes problemáticos centrales en las políticas de prevención social del delito contemporáneas en Argentina y la región.

\section{Conclusiones}

En este artículo, hemos tratado de reconstruir tres producciones del discurso criminológico que establecen fuertes contactos con la problematizaciones sobre la prevención del delito que organizaron el campo de discusiones, debates y posicionamientos del que emergieron en la primera década del siglo XXI las estrategias de prevención social del delito en Argentina. Hemos utilizado para la comparación de las teorías los tres ejes fundamentales que organizaron nuestro relevamiento empírico sobre la prevención en Argentina: el lugar de la política social; las formas de elaboración de la población objetivo; y los modos de territorilización. Como ya hemos adelantado, en diferentes trabajos hemos caracterizado a estas políticas como atravesadas por una forma de problematización de la relación entre condiciones de vida y delito que, si bien emerge como un posicionamiento progresista que intenta introducir una mirada social en el interior de la política criminal (reivindicando el impacto sobre las 'verdaderas' causas sociales del delito) frente a las propuestas punitivistas, descentra la intervención sobre las condiciones de vida y de trabajo de los sujetos como mecanismo preventivo, ubicando a la política social como herramienta externa que permite un conjunto de dispositivos centrados en la transformación subjetiva de los destinatarios. Esta importancia de las capacidades subjetivas en la definición de la población objetivo se articuló con la centralidad del enfoque del desarrollo comunitario, fuertemente atravesado por una idea de cultura comunitaria (Ayos, 2009, 2010, 2011, 2012b, 2013a, 2013b).

En este sentido, consideramos que en dichas intervenciones se retoman algunas líneas de fuerza que atraviesan a las miradas criminológicas que acabamos de analizar: la apelación a la sociología como saber, en el marco de una recuperación del conocimiento en su dimensión científico-técnica; y ensamblado, un posicionamiento ético-político progresista, aunque con marcadas diferencias (socialista positivista, democrático radical o socialdemócrata) en las cuales se recrea una forma específica de la oposición entre represión y prevención como 'invención estratégica' (Donzelot, 2007). 
Los tres discursos se presentan como problematizaciones que emergen de un campo de discusiones plenamente sociológico. En el caso de Ferri, el título de su mayor obra, en la que se presenta la teoría de los equivalentes de las penas que analizamos, Sociología criminal, es expresión de su apuesta por la constitución de una sociología positiva. Además de ser uno de los representantes más importantes de la escuela positiva italiana (junto con Lombroso y Garófalo), es también el que hace mayor hincapié en una multifactorialidad con acento en las condiciones sociales, en detrimento de los factores biológicos y físicos destacados por los otros dos autores (Anitua, 2005; Baratta, 1986). Por otro lado, el campo de disputas que Ferri reconocía tenía una fuerte pertenencia sociológica: son significativos los debates intelectuales con la escuela francesa de criminología, en particular, con Gabriel Tarde. Por su parte, la pertenencia de la producción de la Escuela de Chicago, aunque inscripta en una tradición epistemológica diferente a la de Ferri, como es el pragmatismo norteamericano, es 'plenamente sociológica' (Sozzo, 2008; Gouldner, 2007). En el caso de los realistas de izquierda, su inscripción en la sociología asume un carácter marcadamente polémico, ligado a la apuesta por una criminología que se deshaga de su encierro profesionalista y administrativo para retomar los grandes debates de la teoría sociológica. En buena medida, el libro de Ian Taylor, Paul Walton y Jock Young, La nueva criminología: contribución a una teoría social de la conducta desviada, de 1973, puede interpretarse como un intento de ello, elemento destacado por Alvin Gouldner en su prólogo a la obra.

A su vez, la inscripción en un registro propio de la sociología como ciencia social se liga con un discurso centrado en argumentos científico-técnicos que sustentan la dicotomización u oposición represión-prevención. La crítica a la futilidad de las penas, al antieconómico y obtuso gasto en represión penal, y a la centralidad de la policía en las políticas de control del delito se sustenta en el conocimiento sociológico y en sus técnicas de investigación e intervención para mostrar la racionalidad de esa 'otra' forma de accionar acorde a las causas sociales que muestra la investigación científica: la prevención. Pero esta distinción no solo se asienta en una dimensión científicotécnica, sino que presenta otro eje que destacamos como fundante: una orientación ético-política progresista. Estos discursos se caracterizan por un posicionamiento ético-político que hace hincapié en las reformas sociales como centro de la prevención del delito: desde el socialismo evolucionista 
de Ferri, la posición 'democrática radical' de la Escuela de Chicago en la 'era progresista' norteamericana (Melossi, 1995), hasta el Realismo de Izquierda y su vínculo con la socialdemocracia inglesa (Cohen, 1993; Edwards y Hughes, 2009). Este posicionamiento progresista enfocó el objetivo de la prevención del delito en la noción de causas sociales, expresión de la articulación de los dos registros: causa como parte de esa gramática científica, social como parte de ese ideario político, aunque la forma particular que adoptaron las causas sociales en estos pensamientos tenga divergencias. Ellas refieren, en Ferri, a la influencia de las condiciones de vida de los trabajadores asalariados en el capitalismo industrial sobre la 'criminalidad endémica' (quedando fuera el resto menor de criminalidad determinada por la biología y el ambiente); las áreas de 'desorganización social' o comunitaria en la Escuela de Chicago, que, sin desconocer las condiciones materiales, centraban su explicación en la deficiencia de homogeneización de los patrones culturales en dichas zonas; $y$, por último, la posición de los realistas de izquierda, para quienes las causas sociales del delito se vinculan tanto con las estructuras materiales de las sociedades capitalistas como con sus procesos simbólicos, a partir de la noción de subcultura.

Nos interesa destacar cómo esta orientación preventiva es tributaria de ese proceso descrito por Donzelot de 'invención de lo social', es decir, la creación de un espacio, un ámbito de intervención entre lo civil y lo político: no es a partir del mero ejercicio de la soberanía estatal en la aplicación de la ley penal donde va a encontrarse un fundamento para el desarrollo de las sociedades de masas en los finales del siglo XIX y principios del XX. La Escuela de Chicago organizó una racionalidad política que subraya los procesos de control social situados, concretos, a partir de diversas formas de 'ingeniería' y planificación social para enfrentar lo que es problematizado como la cuestión de la 'integración' y la 'desorganización social', contraponiéndolo a la centralidad del Estado, la soberanía y el derecho. Esta construcción, que ya atravesaba el pensamiento de Ferri y es el sustento de la oposición entre represión y prevención, puede ser entendida como 'invención estratégica' por este discurso sociológico. Es un gesto similar al lugar que tiene la noción de solidaridad durkheimiana en la Tercera República Francesa (Donzelot, 2007).

No obstante, si bien estos elementos surgen como líneas de continuidad, estas tres formas de problematización son construcciones heterogéneas, las 
cuales son puestas a funcionar en las orientaciones que adquirieron las estrategias preventivas en Argentina. La oposición entre represión y prevención que cristalizaba en Ferri abría un espacio de intervención social que luego es retomado por la Escuela de Chicago y los realistas de izquierda. Pero la forma de problematización de lo social, como vimos, es diferente: el enfoque macrosociológico de Ferri y su hincapié en los procesos vinculados a las condiciones de trabajo (de ahí su recuperación de la seguridad social) difieren de la 'escala' local o comunitaria de los sociólogos de Chicago y de la dimensión cultural que destacan en su forma de problematización. Los realistas de izquierda propusieron una mirada de lo social que intentó articular la preocupación por las tensiones estructurales de las sociedades capitalistas, junto con el análisis de los emergentes culturales de dichas tensiones, pero retomando la escala comunitaria en su problematización. En ella vuelve a observarse la orientación del desarrollo comunitario en tanto promoción y activación de las energías comunitarias que había caracterizado las propuestas de Chicago (y las otras 'excepciones' de los años sesenta), construyendo una noción de comunidad que, en tanto espacio defensivo de las nuevas orientaciones actuariales y punitivistas, se ubicaba frente al Estado (en tanto Estado policial), orientación que ya había señalado Melossi (1995) al referirse a la Escuela de Chicago.

La mirada del Realismo de Izquierda (en el marco de una recuperación general de las criminologías 'críticas') ha sido una influencia intensa para las políticas preventivas que analizamos en Argentina. Sin embargo, a partir de esta recuperación, los modos de problematización de la relación entre condiciones de vida y delito que atraviesa a estas intervenciones retoman y tensionan elaboraciones anteriores: aquel hincapié en la oposición entre represión y prevención que organizara el análisis de Ferri puede rastrearse en los programas analizados, en el registro de una macrosociología que hace pie en las transformaciones del trabajo asalariado y las condiciones de vida en las sociedades capitalistas. Al mismo tiempo, estos programas reconstruyen una 'escala' de reflexión e intervención sobre lo urbano 'local', 'comunitaria', con un énfasis en la dimensión cultural de este enfoque, que es heredera de la producción de la Escuela de Chicago (aunque, como analizamos, sus ideas de comunidad y cultura fueran diferentes). Por otro lado, el particular campo de adversidad que construyen los realistas de izquierda (frente a las derivas neoconservadoras y neoliberales) es uno 
de los ejes que marcan la emergencia de las intervenciones preventivas en Argentina, en el contexto del surgimiento de la 'cuestión de la inseguridad' urbana a finales de la década de 1990.

Para terminar, quisiéramos volver a subrayar que estos procesos de reactualización de ciertos problemas y técnicas de intervención nunca son una mera repetición de los otros entramados. Las subsidiariedades o continuidades que marcamos entre estas formas de problematización no significan que en ellas las nociones de prevención, social o comunidad, signifiquen exactamente lo mismo, sino que estas son re-creadas estratégicamente, entretejiéndose en un régimen ni necesario ni absolutamente coherente. Específicamente, nos interesa dar cuenta de cómo políticas preventivas que retoman la mirada multiagencial del Realismo de Izquierda, a partir de su 'escala' comunitaria, reactivan una noción de cultura que no es exactamente la de esta perspectiva, sino que recuperan la relación entre cultura y 'zonas de desorganización' propia de la Escuela de Chicago, que los realistas criticaron. Esta preocupación por las condiciones situadas y particulares de reactualización de modos de problematización puede vincularse, a su vez, con lo que en la 'criminología comparada' se denominó el embeddness o 'radicamento' de las políticas criminales (Nelken, 1994, 2010, 2011; Melossi, 1997; Sozzo, 2008), entendiendo su significación como parte de un particular contexto histórico, político y cultural. Así, la centralidad de la noción de comunidad (en tanto entidad frente al Estado) en la Escuela de Chicago y en los realistas de izquierda retoma una tradición propiamente anglosajona-protestante sobre el Estado en general y la justicia criminal en particular, diferente a las State society como Italia (Nelken, 2010). Como hemos desarrollado, el posicionamiento 'progresista' de las políticas de prevención del delito se desarrolla en Argentina como parte de un proyecto por una 'política democrática de seguridad' que intentó disputar el campo conformado en torno a la 'cuestión de la inseguridad' a las visiones punitivistas. Y, al mismo tiempo, retomó la centralidad de la dimensión comunitaria que atravesaba con fuerza el campo de la política social argentina, concretamente a partir de su articulación con el Programa de Empleo Comunitario. La centralidad de la transformación subjetiva a partir de un eje cultural también tuvo un contexto particular de recuperación: las programáticas del workfare, centradas en las capacidades subjetivas ligadas al 
trabajo, a partir de la lógica de la contraprestación laboral o de capacitación laboral como forma de condicionalidad (Ayos, 2013b).

\section{Referencias}

Anitua, G. (2005). Historia de los pensamientos criminológicos. Buenos Aires: Editores del Puerto.

Ayos, E. (2009). Individualización y prevención 'social' del delito en Argentina: la reactualización de las 'clases peligrosas'. Revista Katálysis, 13(2), Universidade Federal de Santa Catarina.

Ayos, E. (2010). Delito y pobreza: espacios de intersección entre la política criminal y la política social argentina en la primera década del nuevo siglo. São Paulo: IBCCRIM. Ayos, E. (2012a). Prevención del delito y políticas sociales en Argentina: tres ejes problemáticos. Revista de Ciencias Sociales, (135-136), Universidad de Costa Rica.

Ayos, E. (2012b). Comunidad, cultura y prevención social del delito: formas de territorialización en la intersección de la política social y la política criminal. Revista Papeles de Trabajo, (24), Centro Interdisciplinario de Estudios Etnolingüisticos y Antropológicos Sociales, Facultad de Humanidades y Artes, Universidad Nacional de Rosario.

Ayos, E. (2013a). Condiciones de vida y delito, de la emergencia de la 'inseguridad' al ministerio de seguridad. La prevención social del delito como espacio de intersección entre la política social y la política criminal (Argentina, 2000-2010) (Tesis doctoral, Facultad de Ciencias Sociales, Universidad de Buenos Aires, Argentina).

Ayos, E. (2013b). La prevención como contraprestación: la instrumentalidad de la asistencia en la intersección de la política social y la política criminal. Revista Trabajo y Sociedad, (21), Universidad Nacional de Santiago del Estero.

Ayos, E. (2011). Lo social, lo comunitario y lo individual en las estrategias de prevención 'social' del delito en Argentina (2003-2008). Revista de Ciencias Sociales, 7(1), Observatorio Europeo de Tendencias Sociales (Obets), Universidad de Alicante, España.

Baratta, A. (1986). Criminología crítica y crítica del derecho penal. Buenos Aires: Siglo XXI Editores.

Beccaria, C. (1976). De los delitos y las penas. Buenos Aires: EJEA.

Bergalli, R. (2003). El nuevo paradigma criminológico de la exclusión social. En J. Young, La sociedad excluyente. Exclusión social, delito y diferencia en la modernidad tardía. Madrid: Marcial Pons. 
Cid Moliné, J., \& Larrauri Pijoan, E. (2001). Teorías criminológicas. Explicación y prevención de la delincuencia. Barcelona: Ed. Bosch.

Cohen, S. (1993). Escepticismo intelectual y compromiso político: la criminología radical. Revista Delito y Sociedad, (4-5), UBA, Buenos Aires.

Cortés, R. G Marshall, A. (1999). Estrategia económica, instituciones y negociación política en la reforma social de los 90. Revista Desarrollo Económico, (154), IDES, Buenos Aires.

Danani, C. (2004). El alfiler en la silla: sentidos, proyectos y alternativas en el debate de las políticas sociales y de la economía social. Introducción. En C. Danani (Comp.), Política social y economía del trabajo. Buenos Aires: UNGS/OSDE/Altamira.

Daroqui, A. (2003). Las seguridades perdidas. Argumentos, Revista Electrónica del Instituto de Investigaciones Gino Germani, UBA, Buenos Aires.

Daroqui, A. (2009). Muertes silenciadas: la eliminación de los 'delincuentes'. Una mirada sobre las prácticas y los discursos de los medios de comunicación, la policía y la justicia. Buenos Aires: Ediciones del CCC.

Donzelot, J. (1990). La policía de las familias. Valencia: Pre-textos.

Donzelot, J. (2007). La invención de lo social. Ensayo sobre la declinación de las pasiones politicas. Buenos Aires: Nueva Visión.

Ferri, E. (1907). Sociología criminal. Madrid: Góngora.

Font, E. (1999). Transformaciones en el gobierno de la seguridad: análisis exploratorio de conceptos y tendencias. Su relevancia en Argentina. En M. Sozzo (Comp.), Seguridad urbana: nuevos problemas, nuevas perspectivas. Pensar alternativas teóricas y políticas sobre la cuestión criminal. Santa Fe: UNL.

Foucault, M. (2002). La arqueología del saber. Buenos Aires: Siglo XXI Editores.

Galvani, M., Mouzo, K., Ortiz Maldonado, N., Rangugni, V., Recepter, C., Ríos, A., Rodríguez, G., E Seghezzo, G. (2010). A la inseguridad la hacemos entre todos. Prácticas académicas, mediáticas y policiales. Buenos Aires: Hekht Editores.

Gouldner, A. (2007). Prólogo. En I. Taylor, P. Walton, E J. Young, La nueva criminología: contribución a una teoría social de la conducta desviada. Buenos Aires: Amorrortu.

Grassi, E. (2003). Política y problemas sociales en la sociedad neoliberal. La otra década infame. Buenos Aires: Espacio Editorial.

Grondona, A. (2012). 'Tradición' y 'traducción': un estudio de las formas contemporáneas del gobierno de las poblaciones desempleadas en la Argentina (Tesis doctoral, Facultad de Ciencias Sociales, Universidad de Buenos Aires, Argentina).

Guemureman, S. (2002). La contracara de la violencia adolescente-juvenil: la violencia pública institucional de la agencia de control social judicial. En 
S. Gayol \& G. Kessler (Comps.), Violencias, delitos y justicias en la Argentina. Editores Manantial.

Kessler, G. (2002). Entre fronteras desvanecidas. Lógica de articulación entre actividades legales e ilegales en lo jóvenes. En S. Gayol \& G. Kessler (Eds.), Violencias, delitos y justicias en la Argentina. Buenos Aires: Manantial/Universidad Nacional de General Sarmiento.

Kessler, G. (2004). Sociología del delito amateur. Buenos Aires: Paidós.

Kessler, G. (2008). Delito, trabajo y ley. Revista Puentes, (23), Buenos Aires.

Lea, J., E Young, J. (2008). ¿Qué hacer con la ley y el orden? Buenos Aires: Editores del Puerto.

Lea, J., Matthews, R., E Young, J. (1993). El Estado y el control del delito: enfoques relativos a la actividad diversificada de sus agencias. En R. Bergalli (Coord.), Sistema penal e intervenciones sociales. Barcelona: Hacer Editorial.

Matthews, R., E Young, J. (1993). Reflexiones sobre el 'realismo' criminológico. Revista Delito y Sociedad, (3), UBA, Buenos Aires.

Medina Ariza, J. (2010). Políticas de seguridad ciudadana en el contexto urbano y prevención comunitaria. La experiencia anglosajona. Revista Electrónica de Ciencia Penal y Criminología, (12-02), Universidad de Granada.

Melossi, D. (1995). El Estado del control social. México: Siglo XXI Editores.

Melossi, D. (1997). La radicación (embededness) cultural del control social (o de la imposibilidad de la traducción): reflexiones a partir de la comparación de las culturas italiana y norteamericana con respecto al control social. Revista Delito y Sociedad, (9-10), 65-84, Universidad de Buenos Aires.

Merton, R. (1968). Teoría y estructura sociales. México: FCE.

Míguez, D., E Isla, A. (2010). Entre la inseguridad y el temor. Instantáneas de la sociedad actual. Buenos Aires: Paidós.

Park, R. E Burgués, E. (1921). Introduction to the science of sociology. Chicago: The University of Chicago Press.

Pavarini, M. (1983). Control y dominación. México: Siglo XXI Editores.

Pegoraro, J. (1999). Inseguridad urbana y los delitos de la autoridad y el poder.

En M. Sozzo (Ed.), Seguridad urbana: nuevos problemas, nuevos enfoques. Santa Fe: Editorial UNL.

Pegoraro, J. (2001). Inseguridad y violencia en el marco del control social. Espacio Abierto, Cuaderno Venezolano de Sociología, 10(3).

Pegoraro, J. (2002). Teoría sociológica y delito organizado: el eslabón perdido. Encrucijadas UBA, (19), Universidad de Buenos Aires, Buenos Aires.

Rangugni, V. (2004). Transformaciones del Estado y políticas de control del delito en la Argentina de los 90. En Muñagorri \& Pegoraro (Comp.), La relación seguri- 
dad-inseguridad en centros urbanos de Europa y América Latina. Estrategias, politicas, actores, perspectivas, resultados. Madrid: Oñati Proccedings, Editoria Dickinson.

Rangugni, V. (2009). Emergencias, modos de problematización y gobierno de la in/seguridad en la Argentina neoliberal. Delito y Sociedad. Revista de Ciencias Sociales, (27), Buenos Aires.

Rose, N. (1996). The death of the social? Re-figuring the territory of government. Economy and Society, (25), 327-356.

Saín, M. (2002). Seguridad, democracia y reforma del sistema policial en la Argentina. Buenos Aires: Fondo de Cultura Económica.

Saín, M. (2008). El Leviatán Azul. Buenos Aires: Siglo XXI Editores.

Soldano, D., E Andrenacci, L. (2006). Aproximación a las teorías de la política social a partir del caso argentino. En L. Andrenacci (Comp.), Problemas de política social en la Argentina contemporánea. Buenos Aires: Prometeo/UNGS.

Sozzo, M. (1999). Seguridad urbana: nuevos problemas, nuevos enfoques. Santa Fe: UNL.

Sozzo, M. (2000). Seguridad urbana y técnicas de prevención del delito. Cuadernos de Jurisprudencia y Doctrina Penal, (10), Buenos Aires.

Sozzo, M. (2003). Globalización y control del delito. Algunas reflexiones exploratorias. Revista de la Facultad de Ciencias Jurídicas y Sociales, Año 3(3), Ediciones UNL, Santa Fe.

Sozzo, M. (2008). Park, Shaw y McKay y la mirada sociológica sobre el delito en la Escuela de Chicago. Revista Delito y Sociedad, (25), Ediciones UNL, Santa Fe.

Sutherland, E. (1999). El delito de cuello blanco. Madrid: La Piqueta.

Taylor, I., Walton, P., \& Young, J. (2007). La nueva criminología: contribución a una teoría social de la conducta desviada. Buenos Aires: Amorrortu.

Thrasher, F. (2010). La delincuencia juvenil y la prevención del delito. Revista Delito y Sociedad, (29), Ediciones UNL, Santa Fe.

Willis, P. (1997). Aprendiendo a trabajar. Madrid: Ediciones Akal.

Young, J. (2001 ). Canibalismo y bulimia: patrones de control social en la modernidad tardía. Revista Delito y Sociedad, (15-16), Ediciones UNL, Santa Fe.

Young, J. (2003). La sociedad excluyente. Exclusión social, delito y diferencia en la modernidad tardía. Madrid: Marcial Pons.

Young, J. (2008). Merton con energía, Katz con estructura. La sociología del revanchismo y la criminología de la transgresión. Revista Delito y Sociedad, (25), Ediciones UNL, Santa Fe. 